\title{
Photochemistry of atomic oxygen green and red-doublet emissions in comets at larger heliocentric distances
}

\author{
Susarla Raghuram and Anil Bhardwaj
}

\author{
Space Physics Laboratory, Vikram Sarabhai Space Center, 695022 Trivandrum, India \\ e-mail: raghuramsusarla@gmail.com
}

Received 20 May 2013 / Accepted 28 March 2014

\begin{abstract}
Context. In comets, the atomic oxygen green (5577 $\AA$ ) to red-doublet $(6300,6364 \AA$ ) emission intensity ratio (G/R ratio) of 0.1 has been used to confirm $\mathrm{H}_{2} \mathrm{O}$ as the parent species producing forbidden oxygen emission lines. The larger $(>0.1)$ value of $\mathrm{G} / \mathrm{R}$ ratio observed in a few comets is ascribed to the presence of higher $\mathrm{CO}_{2}$ and $\mathrm{CO}$ relative abundances in the cometary coma.

Aims. We aim to study the effect of $\mathrm{CO}_{2}$ and $\mathrm{CO}$ relative abundances on the observed $\mathrm{G} / \mathrm{R}$ ratio in comets observed at large ( $>2$ au) heliocentric distances by accounting for important production and loss processes of $\mathrm{O}\left({ }^{1} \mathrm{~S}\right)$ and $\mathrm{O}\left({ }^{1} \mathrm{D}\right)$ atoms in the cometary coma. Methods. Recently we have developed a coupled chemistry-emission model to study photochemistry of $\mathrm{O}\left({ }^{1} \mathrm{~S}\right)$ and $\mathrm{O}\left({ }^{1} \mathrm{D}\right)$ atoms and the production of green and red-doublet emissions in comets Hyakutake and Hale-Bopp. In the present work we applied the model to six comets where green and red-doublet emissions are observed when they are beyond 2 au from the Sun.

Results. The collisional quenching of $\mathrm{O}\left({ }^{1} \mathrm{~S}\right)$ and $\mathrm{O}\left({ }^{1} \mathrm{D}\right)$ can alter the $\mathrm{G} / \mathrm{R}$ ratio more significantly than that due to change in the relative abundances of $\mathrm{CO}_{2}$ and $\mathrm{CO}$. In a water-dominated cometary coma and with significant $(>10 \%) \mathrm{CO}_{2}$ relative abundance, photodissociation of $\mathrm{H}_{2} \mathrm{O}$ mainly governs the red-doublet emission, whereas $\mathrm{CO}_{2}$ controls the green line emission. If a comet has equal composition of $\mathrm{CO}_{2}$ and $\mathrm{H}_{2} \mathrm{O}$, then $\sim 50 \%$ of red-doublet emission intensity is controlled by the photodissociation of $\mathrm{CO}_{2}$. The role of $\mathrm{CO}$ photodissociation is insignificant in producing both green and red-doublet emission lines and consequently in determining the G/R ratio. Involvement of multiple production sources in the $\mathrm{O}\left({ }^{1} \mathrm{~S}\right)$ formation may be the reason for the observed higher green line width than that of red lines. The G/R ratio values and green and red-doublet line widths calculated by the model are consistent with the observation.

Conclusions. Our model calculations suggest that in low gas production rate comets the G/R ratio greater than 0.1 can be used to constrain the upper limit of $\mathrm{CO}_{2}$ relative abundance provided the slit-projected area on the coma is larger than the collisional zone. If a comet has equal abundances of $\mathrm{CO}_{2}$ and $\mathrm{H}_{2} \mathrm{O}$, then the red-doublet emission is significantly $(\sim 50 \%)$ controlled by $\mathrm{CO}_{2}$ photodissociation and thus the $\mathrm{G} / \mathrm{R}$ ratio is not suitable for estimating $\mathrm{CO}_{2}$ relative abundance.
\end{abstract}

Key words. molecular processes - comets: general

\section{Introduction}

Green $(5577 \AA)$ and red-doublet $(6300,6364 \AA)$ emissions are due to the electronic transition of oxygen atoms from metastable ${ }^{1} \mathrm{~S}$ and ${ }^{1} \mathrm{D}$ states, respectively, to the ground ${ }^{3} \mathrm{P}$ state. Since $O\left({ }^{1} S\right)$ and $O\left({ }^{1} \mathrm{D}\right)$ are metastable states, resonance fluorescence by solar photons is not an effective excitation mechanism for populating these states. Dissociative excitation of O-bearing neutrals by photons and photoelectrons, and thermal recombination of atomic oxygen constituted ions are the sources of these metastable states in the cometary coma (Bhardwaj \& Haider 2002; Bhardwaj \& Raghuram 2012; Raghuram \& Bhardwaj 2013). Most of the comets observed around heliocentric distance of 1 au have $\mathrm{H}_{2} \mathrm{O}$ as the principal constituent in the cometary coma (Bockelée-Morvan et al. 2004). Based on the theoretical work of Festou \& Feldman (1981) green to red-doublet emission intensity ratio (hereafter $\mathrm{G} / \mathrm{R}$ ratio) of 0.1 has customarily been used as a benchmark to confirm the parent source of these prompt emissions as $\mathrm{H}_{2} \mathrm{O}$ in several comets observed around 1 au from the Sun (Cochran 1984, 2008; Morrison et al. 1997; Zhang et al. 2001; Cochran \& Cochran 2001; Furusho et al. 2006; Capria et al. 2005, 2008, 2010). The observed $\mathrm{G} / \mathrm{R}$ ratio of more than 0.1 has been attributed to higher relative abundances of $\mathrm{CO}_{2}$ and $\mathrm{CO}$ (Furusho et al. 2006; Capria et al. 2010; McKay et al. 2012; Decock et al. 2013). Since no experimental cross section or yield for the production of $\mathrm{O}\left({ }^{1} \mathrm{~S}\right)$ from $\mathrm{H}_{2} \mathrm{O}$ is available in the literature, the calculated photorates of Festou \& Feldman (1981) have been questioned by Huestis \& Slanger (2006). In a $\mathrm{H}_{2} \mathrm{O}$-dominated cometary coma, the reddoublet emission intensity is determined by formation and destruction rates of $\mathrm{O}\left({ }^{1} \mathrm{D}\right)$ (Bhardwaj \& Haider 2002; Bhardwaj \& Raghuram 2012; Raghuram \& Bhardwaj 2013). Since the red-doublet emission is mainly governed by photodissociation of $\mathrm{H}_{2} \mathrm{O}$, the observed intensity of $6300 \AA$ has been used to estimate the production rate as well as to understand the spatial distribution of $\mathrm{H}_{2} \mathrm{O}$ in the cometary coma (e.g. Delsemme \& Combi 1976, 1979; Fink \& Johnson 1984; Schultz et al. 1992; Morgenthaler et al. 2001; Furusho et al. 2006).

We have recently developed a coupled chemistry-emission model for the production of green and red-doublet emissions by accounting for important production and loss mechanisms of $\mathrm{O}\left({ }^{1} \mathrm{~S}\right)$ and $\mathrm{O}\left({ }^{1} \mathrm{D}\right)$ atoms. The model has been applied to comets Hyakutake (Bhardwaj \& Raghuram 2012) and Hale-Bopp (Raghuram \& Bhardwaj 2013). Our model calculations showed that in a $\mathrm{H}_{2} \mathrm{O}$-dominated cometary coma more than $90 \%$ of the $\mathrm{O}\left({ }^{1} \mathrm{D}\right)$ is populated via photodissociative excitation of $\mathrm{H}_{2} \mathrm{O}$ and the rest through photodissociation of $\mathrm{CO}_{2}$ and $\mathrm{CO}$. We also demonstrated that the $\mathrm{G} / \mathrm{R}$ ratio depends not only on the photochemistry involved in the formation of $\mathrm{O}\left({ }^{1} \mathrm{D}\right)$ 
and $\mathrm{O}\left({ }^{1} \mathrm{~S}\right)$, but also on the projected area observed on the comet, which is a function of slit dimension and geocentric distance of the comet (Bhardwaj \& Raghuram 2012). The model calculations on comets Hyakutake and Hale-Bopp showed that the intensity of the [OI] $6300 \AA$ line is largely governed by photodissociation of $\mathrm{H}_{2} \mathrm{O}$, whereas the [OI] $5577 \AA$ emission line is mainly controlled by the photodissociation of both $\mathrm{H}_{2} \mathrm{O}$ and $\mathrm{CO}_{2}$. It is also suggested that $\mathrm{CO}_{2}$ can produce $\mathrm{O}\left({ }^{1} \mathrm{~S}\right)$ more efficiently than $\mathrm{H}_{2} \mathrm{O}$. The calculated mean excess energy profiles in various photodissociation processes showed that the photodissociation of $\mathrm{CO}_{2}$ can produce $\mathrm{O}\left({ }^{1} \mathrm{~S}\right)$ with higher excess velocity compared to the photodissociation of $\mathrm{H}_{2} \mathrm{O}$ (Raghuram \& Bhardwaj 2013). All these calculations are carried out at $\sim 1$ au.

At larger heliocentric distances the cometary coma is composed of larger proportions of $\mathrm{CO}$ and $\mathrm{CO}_{2}$ than at 1 au (Meech \& Svoreň 2004; Crovisier et al. 1999; Biver et al. 1997, 1999; Bockelée-Morvan et al. 2004, 2010). At heliocentric distances of more than 2 au the prompt emissions of atomic oxygen are observed in several comets, viz. C/2007 Q3 (Siding Spring), C/2006 W3 (Christensen), C/2009 P1 (Garradd), C/2001 Q4 (NEAT), 116P/Wild 4, and C/2003 K4 (LINEAR) (Furusho et al. 2006; McKay et al. 2012; Decock et al. 2013). Assuming that $\mathrm{CO}_{2}$ and $\mathrm{CO}$ are the main sources of green and red-doublet emissions, the observed $\mathrm{G} / \mathrm{R}$ ratio in comets at large heliocentric distances ( $>2 \mathrm{au}$ ) has been used to estimate the $\mathrm{CO}_{2}$ abundance in comets (Decock et al. 2013; McKay et al. 2012).

The present study is aimed at studying the photochemistry of $\mathrm{O}\left({ }^{1} \mathrm{~S}\right)$ and $\mathrm{O}\left({ }^{1} \mathrm{D}\right)$ atoms and associated green and red-doublet emission production mechanisms in the above mentioned six comets at larger heliocentric distance $(>2 \mathrm{au})$ where the gas production rate of $\mathrm{CO}$ can be equal to that of $\mathrm{H}_{2} \mathrm{O}$. One of the objectives of the study is to verify whether the $G / R$ ratio value can be used to infer the $\mathrm{CO}_{2}$ relative abundance, with respect to $\mathrm{H}_{2} \mathrm{O}$, in the comets that are observed at larger heliocentric distances. In this study we have shown that even at large heliocentric distances, the photodissociation of $\mathrm{CO}$ is only a minor source of $\mathrm{O}\left({ }^{1} \mathrm{~S}\right)$ and $\mathrm{O}\left({ }^{1} \mathrm{D}\right)$ atoms, and its impact on the $\mathrm{G} / \mathrm{R}$ ratio is negligible. The red-doublet emission intensity is mainly governed by $\mathrm{H}_{2} \mathrm{O}$, while the green line emission intensity is controlled by $\mathrm{CO}_{2}$. We have also demonstrated that collisional quenching can significantly change the observed $\mathrm{G} / \mathrm{R}$ ratio and that its impact on the $\mathrm{G} / \mathrm{R}$ ratio is much greater than that due to variation in the $\mathrm{CO}_{2}$ and $\mathrm{H}_{2} \mathrm{O}$ abundances.

\section{Model}

The details of model and the photochemical reactions considered in the model are presented in our previous works (Bhardwaj \& Raghuram 2012; Raghuram \& Bhardwaj 2013). Here we present the input parameters that have been used in the model for the calculation of green and red-doublet emission intensities for the observed conditions of six comets (viz. 116P/Wild 4, C/2003 K4 (LINEAR), C/2007 Q3 (Siding Spring), C/2006 W3 (Christensen), C/2009 P1 (Garradd), C/2001 Q4 (NEAT)). The photochemical reaction network and cross sections of photon and electron impact processes that have been considered in our previous work remain the same for the present calculation. The photoelectron impact excitation reactions are accounted for by degrading solar extreme ultraviolet (EUV) generated photoelectrons and electron impact cross sections in the cometary coma using the analytical yield spectrum (AYS) technique which is based on the Monte Carlo method. Details of the AYS approach and the method for calculating photoelectron flux and excitation rates are given in our earlier papers and references therein (Bhardwaj 1999; Haider \& Bhardwaj 2005; Bhardwaj \& Raghuram 2011, 2012; Raghuram \& Bhardwaj 2012). The production and loss mechanisms for the $\mathrm{O}\left({ }^{1} \mathrm{~S}\right)$ and $\mathrm{O}\left({ }^{1} \mathrm{D}\right)$ considered in the model calculations are presented in our previous papers (Bhardwaj \& Raghuram 2012; Raghuram \& Bhardwaj 2013). Only the dominant O-bearing neutral species $\mathrm{H}_{2} \mathrm{O}, \mathrm{CO}_{2}$, and $\mathrm{CO}$ are considered in the present model.

The neutral gas production rates used in the model calculations for different comets during observation periods of oxygen emission lines are tabulated in Table 1. In some comets these gas production rates are not measured, and so we have made a reasonable approximation to incorporate $\mathrm{CO}_{2}$ and $\mathrm{CO}$ in the model. However, we vary the $\mathrm{CO}_{2}$ and $\mathrm{CO}$ relative abundances on these comets to assess the impact on the green and reddoublet emission intensities and subsequently on the $G / R$ ratio.

Furusho et al. (2006) observed the forbidden oxygen lines in comet 116P/Wild 4 when it was at 2.4 au from the Sun. Using the infrared satellite AKARI, Ootsubo et al. (2012) measured the $\mathrm{H}_{2} \mathrm{O}$ production rate in this comet as $\sim 1 \times 10^{27} \mathrm{~s}^{-1}$ and abundance of $\mathrm{CO}_{2}$ was found to be $10 \%$ relative to the water at heliocentric distance of $2.22 \mathrm{au}$. Ootsubo et al. (2012) also determined the upper limit for $\mathrm{CO}$ abundance in this comet as $20 \%$ relative to water. In our model we have used these measured gas production rates and relative abundances as input assuming that these values did not vary significantly in this comet from 2.2 au to 2.4 au.

Using the Spitzer space telescope, Woodward et al. (2007) measured the $\mathrm{H}_{2} \mathrm{O}$ production rate in comet $\mathrm{C} / 2003 \mathrm{~K} 4$ (LINEAR) as $2.43 \times 10^{29} \mathrm{~s}^{-1}$ when the comet was at $1.76 \mathrm{au}$ from the Sun during pre-perihelion. Decock et al. (2013) observed atomic oxygen forbidden lines in this comet when it was at 2.6 au heliocentric distance. Since the $\mathrm{H}_{2} \mathrm{O}$ production rate was not measured at 2.6 au we scaled the Woodward et al. (2007) measured $\mathrm{H}_{2} \mathrm{O}$ production rate to heliocentric distance of $2.6 \mathrm{au}$ assuming that it varies as the inverse square of heliocentric distance. However, we evaluate the impact of the estimated $\mathrm{H}_{2} \mathrm{O}$ production rate on the calculated $\mathrm{G} / \mathrm{R}$ by decreasing its value by a factor of 2 . Since $\mathrm{CO}_{2}$ and $\mathrm{CO}$ are not observed in this comet we have assumed their abundances to be $10 \%$ and $25 \%$ relative to $\mathrm{H}_{2} \mathrm{O}$, respectively. We show that $\mathrm{CO}$ does not play a significant role in determining green and red-doublet emission line intensities, whereas the $\mathrm{CO}_{2}$ abundance is important in determining the $\mathrm{G} / \mathrm{R}$ ratio.

In comet C/2007 Q3 (Siding Spring), only the [OI] $6300 \AA$ emission line was observed and the intensity of [OI] $5577 \AA$ was estimated with a $3 \sigma$ upper limit when it was at a heliocentric distance of 2.96 au (McKay et al. 2012). The AKARI satellite detected both $\mathrm{H}_{2} \mathrm{O}$ and $\mathrm{CO}_{2}$ in comet $\mathrm{C} / 2007 \mathrm{Q} 3$ during its pre-perihelion period and measured the $\mathrm{CO}_{2}$ relative abundance as $17 \%$ relative to $\mathrm{H}_{2} \mathrm{O}$ production rate when the comet was at a heliocentric distance of 3.3 au (Ootsubo et al. 2012). Assuming that the photodissociation of $\mathrm{H}_{2} \mathrm{O}$ is the major source for the observed [OI] $6300 \AA$ emission, McKay et al. (2012) inferred the $\mathrm{H}_{2} \mathrm{O}$ production rate in comet $\mathrm{C} / 2007 \mathrm{Q} 3$ as $1.8 \times 10^{27} \mathrm{~s}^{-1}$ which is smaller by a factor of 2 than the Ootsubo et al. (2012) measurement. Ootsubo et al. (2012) observation covers a larger $\left(43^{\prime \prime} \times 43^{\prime \prime}\right)$ projected area on the coma which can account for most of the $\mathrm{H}_{2} \mathrm{O}$ produced from extended distributed sources like icy grains in the coma in the observed field of view compared to that of the McKay et al. (2012) observation $\left(3.2^{\prime \prime} \times 1.62^{\prime \prime}\right)$. Hence, we have used the Ootsubo et al. (2012) measured gas production rates in the model. We have taken the $\mathrm{H}_{2} \mathrm{O}$ production rate on comet $\mathrm{C} / 2007 \mathrm{Q} 3$ as $4 \times 10^{27} \mathrm{~s}^{-1}$ 
Table 1. Observational conditions (slit dimension, heliocentric $(r)$, and geocentric $(\Delta)$ distances) of various comets, corresponding $\mathrm{H}_{2} \mathrm{O}$ production rates and $\mathrm{CO}_{2}$ and $\mathrm{CO}$ relative abundances relative to $\mathrm{H}_{2} \mathrm{O}$, and comparison of calculated green to red-doublet emission intensity ratios $(\mathrm{G} / \mathrm{R}$ ratio) with the observations.

\begin{tabular}{lccccccccc}
\hline \hline Comet & $\begin{array}{c}r \\
(\mathrm{au})\end{array}$ & $\begin{array}{c}\Delta \\
(\mathrm{au})\end{array}$ & $\begin{array}{c}\text { Slit dimension } \\
\left({ }^{\prime \prime} \times \times^{\prime \prime}\right)\end{array}$ & $\begin{array}{c}\mathrm{Q}\left(\mathrm{H}_{2} \mathrm{O}\right) \\
\left(\mathrm{s}^{-1}\right)\end{array}$ & $\begin{array}{c}\mathrm{CO}_{2}^{\dagger} \\
(\%)\end{array}$ & $\begin{array}{r}\mathrm{CO}^{\dagger} \\
(\%)\end{array}$ & $\begin{array}{c}\mathrm{G} / \mathrm{R} \text { ratio } \\
\text { cal. }\end{array}$ & obs. & Referencell \\
\hline 116P/Wild 4 & 2.40 & 1.4 & $8 \times 1$ & $1 \times 10^{27 *}$ & 10 & 20 & 0.09 & 0.15 & Furusho et al. (2006) \\
C/2003 K4 (LINEAR) & 2.60 & 2.36 & $0.80 \times 11$ & $1 \times 10^{29 \dagger}$ & $10^{\ddagger}$ & $25^{\ddagger}$ & 0.09 & 0.09 & Decock et al. (2013) \\
C/2007 Q3 (Siding Spring) & 2.96 & 2.48 & $3.20 \times 1.6$ & $4 \times 10^{27 *}$ & 17 & 10 & 0.12 & 0.20 & McKay et al. (2012) \\
C/2006 W3 (Christensen) & 3.13 & 2.35 & $3.20 \times 1.6$ & $2.0 \times 10^{28 *}$ & 42 & 98 & 0.18 & $0.24 \pm 0.08$ & McKay et al. (2012) \\
C/2009 P1 (Garradd) & 3.25 & 3.50 & $0.44 \times 12$ & $2.3 \times 10^{27 * * *}$ & $25^{\ddagger}$ & $100^{\ddagger}$ & 0.14 & 0.21 & Decock et al. (2013) \\
C/2001 Q4 (NEAT) & 3.70 & 3.40 & $0.45 \times 11$ & $3.8 \times 10^{27 * *}$ & $75^{\ddagger}$ & $100^{\ddagger}$ & 0.23 & 0.33 & Decock et al. (2013) \\
Comet X & 3.70 & 3.40 & $0.45 \times 11$ & $4 \times 10^{27}$ & 100 & 100 & 0.25 & - & - \\
\hline
\end{tabular}

Notes. ${ }^{(*)}$ Ootsubo et al. (2012); ${ }^{(* *)}$ Combi et al. (2009); ${ }^{(* *)}$ Bodewits et al. (2012); ${ }^{(\ddagger)}$ assumed; ${ }^{(\dagger)}$ see text; ${ }^{(\$)}$ comet X is a hypothetical comet similar to the observational condition of comet NEAT, but having equal gas production rate of $\mathrm{H}_{2} \mathrm{O}, \mathrm{CO}_{2}$, and $\mathrm{CO}$; cal. = Calculated, obs. = Observation. ${ }^{(\|)}$Reference is for the observed G/R ratio value on the corresponding comet.

with $17 \%$ and $10 \%$ relative abundances of $\mathrm{CO}_{2}$ and $\mathrm{CO}$ with respect to water, respectively, in our model.

By making radio observations on comet $\mathrm{C} / 2006 \mathrm{~W} 3$ (Christensen), Bockelée-Morvan et al. (2010) derived $\mathrm{H}_{2} \mathrm{O}$ and $\mathrm{CO}$ production rates as $4.2 \times 10^{28}$ and $3.9 \times 10^{28} \mathrm{~s}^{-1}$, respectively. During this measurement the comet was at a heliocentric distance of $3.2 \mathrm{au}$. These values are higher by a factor of 2 compared to the infrared satellite observed values reported by Ootsubo et al. (2012) which were derived when the comet was nearly at the same heliocentric distance. Ootsubo et al. (2012) reported $42 \%$ and $98 \%$ of $\mathrm{CO}_{2}$ and $\mathrm{CO}$ abundances relative to $\mathrm{H}_{2} \mathrm{O}$, respectively, in this comet when it was at $3.13 \mathrm{au}$. During the green and red-doublet emission observation, comet C/2006 W3 was at a heliocentric distance of 3.13 au (McKay et al. 2012). For this comet we have used the Ootsubo et al. (2012) measured $\mathrm{H}_{2} \mathrm{O}$ production rate as well as $\mathrm{CO}_{2}$ and $\mathrm{CO}$ relative abundances in our model.

The $\mathrm{H}_{2} \mathrm{O}$ production rate in comet $\mathrm{C} / 2009 \mathrm{P} 1$ (Garradd) beyond 2 au has been reported by various workers (Paganini et al. 2012; Villanueva et al. 2012; Bodewits et al. 2012; Combi et al. 2013; Farnham et al. 2012; Feaga et al. 2012). Using the Swift satellite, Bodewits et al. (2012) observed the OH $3080 \AA$ Amission line in comet $\mathrm{C} / 2009 \mathrm{P} 1$ and derived the $\mathrm{H}_{2} \mathrm{O}$ production rate when it was between 2 au and 4 au heliocentric distances. We have taken $\mathrm{H}_{2} \mathrm{O}$ production at 3.25 au from the Sun as $2.3 \times 10^{27} \mathrm{~s}^{-1}$ by linearly interpolating the Bodewits et al. (2012) derived production rates between 3 au and 3.5 au heliocentric distances. Decock et al. (2013) used the observed G/R ratio at 3.25 au and estimated that around $25 \% \mathrm{CO}_{2}$ abundance relative to $\mathrm{H}_{2} \mathrm{O}$ was present in this comet. We assumed $25 \% \mathrm{CO}_{2}$ relative abundance in the coma of comet C/2009 P1 in the model. Since $\mathrm{CO}$ is highly volatile and the comet is at a large heliocentric distance we assumed that the gas production rates for $\mathrm{H}_{2} \mathrm{O}$ and $\mathrm{CO}$ are equal in this comet.

In comet $\mathrm{C} / 2001 \mathrm{Q} 4$ (NEAT), the $\mathrm{H}_{2} \mathrm{O}$ production rate is measured by Biver et al. (2009) and Combi et al. (2009) at different heliocentric distances using hydrogen Ly- $\alpha(1216 \AA)$ and radio (557 GHz) emissions, respectively. Combi et al. (2009) fitted the observed $\mathrm{H}_{2} \mathrm{O}$ production rate as a function of heliocentric distance $\left(r_{\mathrm{h}}\right)$ as $3.5 \times 10^{29} \times r_{\mathrm{h}}^{-1.7} \mathrm{~s}^{-1}$. We used this expression to calculate the $\mathrm{H}_{2} \mathrm{O}$ production rate in this comet at 3.7 au where the green and red-doublet emissions were observed (Decock et al. 2013). Since the comet is at a large heliocentric distance we assumed that the $\mathrm{CO}$ and $\mathrm{H}_{2} \mathrm{O}$ abundances are equal. Based on the observed G/R ratio on this comet, Decock et al. (2013) suggested that the $\mathrm{CO}_{2}$ relative abundance in this comet could be between $60 \%$ and $80 \%$ with respect to $\mathrm{H}_{2} \mathrm{O}$. In our model we have assumed the $\mathrm{CO}_{2}$ relative abundance at 3.7 au heliocentric distance to be $75 \%$.

To evaluate the individual contributions of major O-bearing species in producing green and red-doublet emissions and their affect on the $\mathrm{G} / \mathrm{R}$ ratio we have made a case study for a hypothetical comet $\mathrm{X}$ in which we assumed equal gas production of $\mathrm{H}_{2} \mathrm{O}, \mathrm{CO}_{2}$, and $\mathrm{CO}$ in the comet. This is similar to the observation of Ootsubo et al. (2012) on comet C/2006 W3 in which it is found that $\mathrm{CO}_{2}$ and $\mathrm{H}_{2} \mathrm{O}$ gas production rates are equal $\left(\sim 8 \times 10^{27} \mathrm{~s}^{-1}\right)$; however, the $\mathrm{CO}$ production rate is around 3 times higher when the comet was at 3.7 au from the Sun.

The solar flux, which is required to calculate photorates of different species, is taken from the SOLAR2000 (S2K) v.2.36 model of Tobiska (2004) at $1 \mathrm{au}$ and scaled according to the observed heliocentric distance of different comets. The electron temperature that determines the dissociative recombination rates of ions is taken as constant $300 \mathrm{~K}$ in the cometary coma. The effect of this constant temperature profile on the model calculation is discussed later. The yield of $\mathrm{O}\left({ }^{1} \mathrm{~S}\right)$ at solar H Ly- $\alpha$ in the photodissociation of $\mathrm{H}_{2} \mathrm{O}$ is taken as $0.5 \%$. The impact of this assumption was discussed in our previous work (Bhardwaj $\&$ Raghuram 2012). The photodissociative excitation cross section for $\mathrm{CO}_{2}$ producing $\mathrm{O}\left({ }^{1} \mathrm{D}\right)$ is taken from Jain (2013). The photorate for the production of $\mathrm{O}\left({ }^{1} \mathrm{~S}\right)$ from the photodissociation of $\mathrm{CO}$ has been taken from the theoretically estimated value of Festou \& Feldman (1981) and scaled to the observed heliocentric distance.

\section{Results}

Since these comets have different water production rates (varying from $10^{27}$ to $10^{29} \mathrm{~s}^{-1}$ ), as well as different $\mathrm{CO}_{2}$ and $\mathrm{CO}$ relative abundances with respect to $\mathrm{H}_{2} \mathrm{O}$, we present calculations in comet $\mathrm{C} / 2006 \mathrm{~W} 3$ which is followed by a discussion on the calculated results for other comets.

\subsection{Production processes of $O\left({ }^{1} S\right)$ and $O\left({ }^{1} D\right)$}

The calculated production rates for the $\mathrm{O}\left({ }^{1} \mathrm{~S}\right)$ from different processes in comet C/2006 W3 are presented in Fig. 1. The major production source of oxygen atoms in the ${ }^{1} \mathrm{~S}$ metastable state is photodissociation of $\mathrm{CO}_{2}$ followed by photodissociation of $\mathrm{CO}$ and $\mathrm{H}_{2} \mathrm{O}$. The contribution from the photoelectron impact excitation reactions is smaller compared to photodissociative excitation processes. Above $10^{3} \mathrm{~km}$, the dissociative recombination 


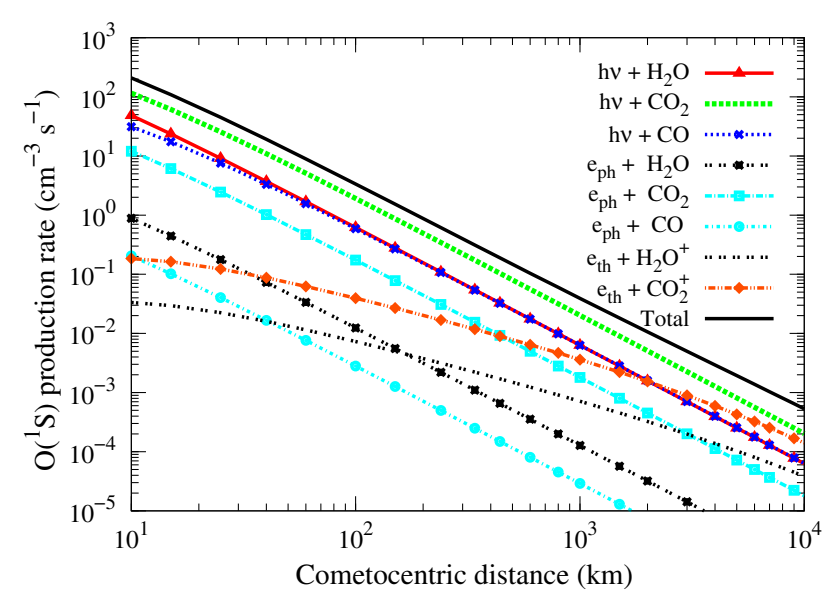

Fig. 1. Calculated volumetric $\mathrm{O}\left({ }^{1} \mathrm{~S}\right)$ production rate profiles for major production mechanisms in comet $\mathrm{C} / 2006 \mathrm{~W} 3$ (Christensen) with $\mathrm{H}_{2} \mathrm{O}$ production rate of $2 \times 10^{28} \mathrm{~s}^{-1}$ and $42 \% \mathrm{CO}_{2}$ and $98 \% \mathrm{CO}$ abundances relative to $\mathrm{H}_{2} \mathrm{O}$ in the cometary coma when the comet was at 3.13 au heliocentric distance. $\mathrm{h} v$ : solar photon; $\mathrm{e}_{p h}$ : photoelectron; and $\mathrm{e}_{\mathrm{th}}$ : thermal electron.

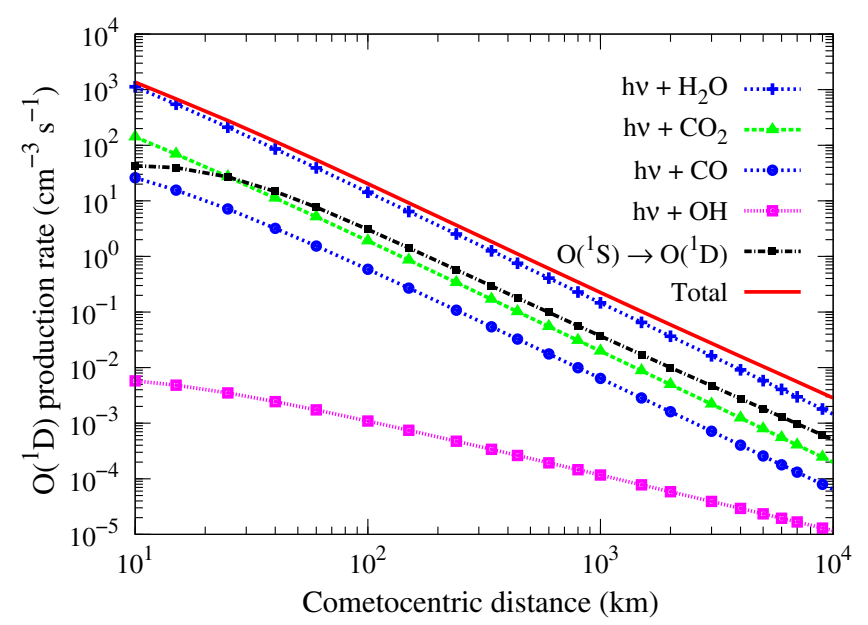

Fig. 2. Calculated volumetric $\mathrm{O}\left({ }^{1} \mathrm{D}\right)$ production rate profiles for major production mechanisms in comet $\mathrm{C} / 2006 \mathrm{~W} 3$ (Christensen) with $\mathrm{H}_{2} \mathrm{O}$ production rate of $2 \times 10^{28} \mathrm{~s}^{-1}$ and $42 \% \mathrm{CO}_{2}$ and $98 \% \mathrm{CO}$ relative abundances with respect to $\mathrm{H}_{2} \mathrm{O}$ in the cometary coma when the comet was at $3.13 \mathrm{au}$ from the Sun. $\mathrm{h} v$ : solar photon.

of $\mathrm{CO}_{2}^{+}$also contributes significantly. The solar flux in wavelength bin $955-1165 \AA$ is the main source that dissociates $\mathrm{CO}_{2}$ and produces atomic oxygen in the ${ }^{1} \mathrm{~S}$ state. Since the yield for photodissociation of $\mathrm{CO}_{2}$ in this wavelength bin is almost unity, the absorption of solar photons of this wavelength bin by $\mathrm{CO}_{2}$ leads to the formation of $\mathrm{O}\left({ }^{1} \mathrm{~S}\right)$ and $\mathrm{CO}$ (Raghuram \& Bhardwaj 2013; Bhardwaj \& Raghuram 2012).

The calculated $\mathrm{O}\left({ }^{1} \mathrm{D}\right)$ production rate profiles for different mechanisms are shown in Fig. 2. The major production of $\mathrm{O}\left({ }^{1} \mathrm{D}\right)$ is via photodissociation of $\mathrm{H}_{2} \mathrm{O}$, but close to the nucleus $(<30 \mathrm{~km})$ photodissociation of $\mathrm{CO}_{2}$ is also a significant $\mathrm{O}\left({ }^{1} \mathrm{D}\right)$ production process, and above $30 \mathrm{~km}$ the radiative decay of $\mathrm{O}\left({ }^{1} \mathrm{~S}\right)$ becomes a more important source of $\mathrm{O}\left({ }^{1} \mathrm{D}\right)$ than the former. The photodissociation of $\mathrm{CO}$ and $\mathrm{OH}$ are minor production sources of $\mathrm{O}\left({ }^{1} \mathrm{D}\right)$. Most of the $\mathrm{O}\left({ }^{1} \mathrm{D}\right)$ production $(>95 \%)$ is due to photodissociation of $\mathrm{H}_{2} \mathrm{O}$ by solar $\mathrm{H} \mathrm{Ly}-\alpha$ photon flux.

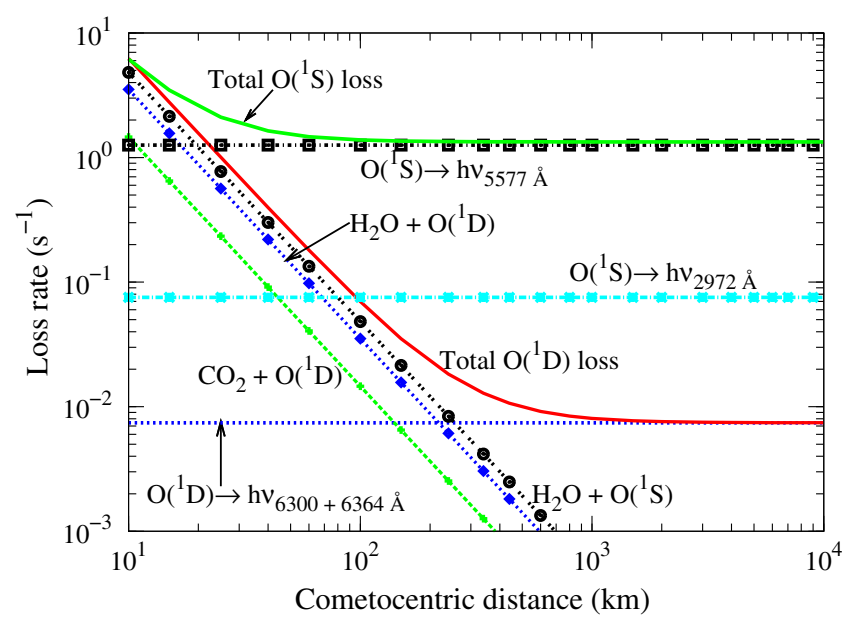

Fig. 3. Calculated radial loss rate profiles for major loss mechanisms of the $\mathrm{O}\left({ }^{1} \mathrm{D}\right)$ and $\mathrm{O}\left({ }^{1} \mathrm{~S}\right)$ in comet $\mathrm{C} / 2006 \mathrm{~W} 3$ (Christensen) with $\mathrm{H}_{2} \mathrm{O}$ production rate of $2 \times 10^{28} \mathrm{~s}^{-1}$ and $42 \% \mathrm{CO}_{2}$ and $98 \% \mathrm{CO}$ abundances relative to $\mathrm{H}_{2} \mathrm{O}$ in the cometary coma when the comet was at 3.13 au from the Sun.

\subsection{Loss processes of $O\left({ }^{1} S\right)$ and $O\left({ }^{1} D\right)$}

The calculated $\mathrm{O}\left({ }^{1} \mathrm{~S}\right)$ and $\mathrm{O}\left({ }^{1} \mathrm{D}\right)$ destruction rate profiles in comet C/2006 W3 are presented in Fig. 3. Since this comet has a low neutral gas production rate, the collisional quenching is a dominant $\mathrm{O}\left({ }^{1} \mathrm{~S}\right)$ destructive mechanism only close to the nucleus $(<30 \mathrm{~km})$. The radiative decay which produces photons at $5577 \AA$ and $2972 \AA$ is the major loss process for $\mathrm{O}\left({ }^{1} \mathrm{~S}\right)$ throughout the coma. The calculated loss rate profiles of $\mathrm{O}\left({ }^{1} \mathrm{D}\right)$ by various processes are also presented in the same figure. Below $300 \mathrm{~km}$, quenching by $\mathrm{H}_{2} \mathrm{O}$ and $\mathrm{CO}_{2}$ are the dominant loss mechanisms of the $\mathrm{O}\left({ }^{1} \mathrm{D}\right)$. Above $300 \mathrm{~km}$, the radiative decay, which results in the emission of photons at $6300 \AA$ and $6364 \AA$, is a major loss process for $\mathrm{O}\left({ }^{1} \mathrm{D}\right)$. Quenching by $\mathrm{CO}$ is a minor loss process for $\mathrm{O}\left({ }^{1} \mathrm{D}\right)$ which is not shown in the figure.

The calculated number density profiles of $\mathrm{O}\left({ }^{1} \mathrm{~S}\right)$ and $\mathrm{O}\left({ }^{1} \mathrm{D}\right)$ in comet $\mathrm{C} / 2006 \mathrm{~W} 3$ along with parent species $\mathrm{H}_{2} \mathrm{O}, \mathrm{CO}_{2}$, and $\mathrm{CO}$ are presented in Fig. 4. Close to the cometary nucleus the flatness in the calculated $\mathrm{O}\left({ }^{1} \mathrm{~S}\right)$ and $\mathrm{O}\left({ }^{1} \mathrm{D}\right)$ number density profiles is due to collisional quenching by cometary species (mainly $\mathrm{H}_{2} \mathrm{O}$ ) and depends on the neutral gas production rate of the comet.

\section{3. [OI] green to red-doublet emission intensity ratio and line widths}

The calculated number density profiles shown in Fig. 4 are multiplied with Einstein emission transition probabilities (see Table 1 in Raghuram \& Bhardwaj 2013) to obtain emission rates. By integrating these emission rates along the line of sight we calculated the emission intensities of green and red-doublet lines as a function of projected distance. The calculated surface brightness profiles for [OI] $5577 \AA$ and red-doublet $(6300+6364 \AA)$ emissions are shown in Fig. 5 with solid curves. It can be seen in this figure that close to the nucleus (below $40 \mathrm{~km}$ projected distance) the green line emission is more intense than the reddoublet emission, which is mainly due to the $\mathrm{O}\left({ }^{1} \mathrm{~S}\right)$ emission rate $\left(1.26 \mathrm{~s}^{-1}\right)$ being higher by about two orders of magnitude compared to that of $\mathrm{O}\left({ }^{1} \mathrm{D}\right)\left(8.59 \times 10^{-3} \mathrm{~s}^{-1}\right)$. The calculated $\mathrm{G} / \mathrm{R}$ ratio in comet $\mathrm{C} / 2006 \mathrm{~W} 3$, which is shown with a dashed curve ("with CO") in Fig. 5, varies between 1.8 and $\sim 0.2$. In the same 


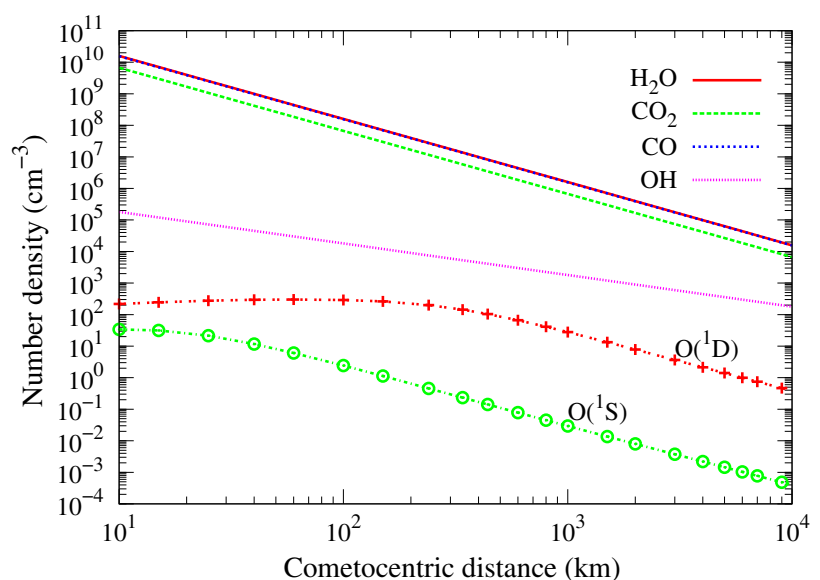

Fig. 4. Calculated number density profiles of $\mathrm{O}\left({ }^{1} \mathrm{~S}\right), \mathrm{O}\left({ }^{1} \mathrm{D}\right)$, and $\mathrm{OH}$, along with those of $\mathrm{H}_{2} \mathrm{O}, \mathrm{CO}$, and $\mathrm{CO}_{2}$ in comet $\mathrm{C} / 2006 \mathrm{~W} 3$ (Christensen) with $\mathrm{H}_{2} \mathrm{O}$ production rate of $2 \times 10^{28} \mathrm{~s}^{-1}$ and $42 \% \mathrm{CO}_{2}$ and $98 \% \mathrm{CO}$ relative abundances with respect to $\mathrm{H}_{2} \mathrm{O}$ in the cometary coma when the comet was at 3.13 au from the Sun.

figure the calculated $\mathrm{G} / \mathrm{R}$ ratio profiles for different cases are also presented. Since there is an uncertainty in the photo-rate of $\mathrm{CO}$ in producing $\mathrm{O}\left({ }^{1} \mathrm{~S}\right)$, which is discussed later, we also did calculations for the $\mathrm{G} / \mathrm{R}$ ratio neglecting this source mechanism which is shown in Fig. 5 with dotted curve ("without CO"). In this case the calculated $\mathrm{G} / \mathrm{R}$ ratio varies between 1.6 and 0.18 . Since comet $\mathrm{C} / 2006 \mathrm{~W} 3$ has a very low gas production rate the collisional quenching may be less important. To assess the effect of collisional quenching on the green and red-doublet emissions, we calculated the $\mathrm{G} / \mathrm{R}$ ratio without considering collisional destruction mechanisms of $\mathrm{O}\left({ }^{1} \mathrm{~S}\right)$ and $\mathrm{O}\left({ }^{1} \mathrm{D}\right)$. In this case the calculated $\mathrm{G} / \mathrm{R}$ ratio is a constant value of 0.18 throughout the coma which is represented with the dash-dotted line in Fig. 5.

Similarly, all these calculations have been carried out on other comets. Considering both collisional quenching and photodissociation of $\mathrm{CO}$, the calculated $\mathrm{G} / \mathrm{R}$ ratio profiles as a function of projected distance in six comets are presented in Fig. 6. This figure shows that close to the nucleus in comets C/2006 W3 and $\mathrm{C} / 2001 \mathrm{Q} 4$, the calculated $\mathrm{G} / \mathrm{R}$ ratio value is more than one which is due to higher $\mathrm{CO}_{2}$ relative abundances and strong collisional quenching of $\mathrm{O}\left({ }^{1} \mathrm{D}\right)$ by cometary species, whereas in other comets this value is always less than one throughout the coma. In comets $\mathrm{C} / 2006 \mathrm{~W} 3$ and $\mathrm{C} / 2001 \mathrm{Q} 4$, the $\mathrm{CO}_{2}$ abundances are very large (see Table 1) and no significant collisional quenching of $\mathrm{O}\left({ }^{1} \mathrm{~S}\right)$. Thus, the green line intensity throughout the coma is determined by $\mathrm{CO}_{2}$ and subsequently the $\mathrm{G} / \mathrm{R}$ ratio governed by the quenching of $\mathrm{O}\left({ }^{1} \mathrm{D}\right)$ depending on the $\mathrm{H}_{2} \mathrm{O}$ production rate. In other comets the $\mathrm{G} / \mathrm{R}$ ratio is small because of lower $\mathrm{CO}_{2}$ abundances compared to former comets.

We calculated the average G/R ratio over the observed projected area on each comet. The projected area on a comet changes with the dimension of slit used for observation and the geocentric distance of comet. The calculated averaged G/R ratios on different comets are tabulated in Table 1 along with the values derived from observations. Our calculated G/R ratio values are comparable (within a factor of two) with the observations on different comets observed at different heliocentric and geocentric distances.

The percentage contributions for various production processes involved in the formation of $\mathrm{O}\left({ }^{1} \mathrm{~S}\right)$ and $\mathrm{O}\left({ }^{1} \mathrm{D}\right)$ in these comets at three different projected distances are given in Table 2. These calculations suggest that in all these comets, the

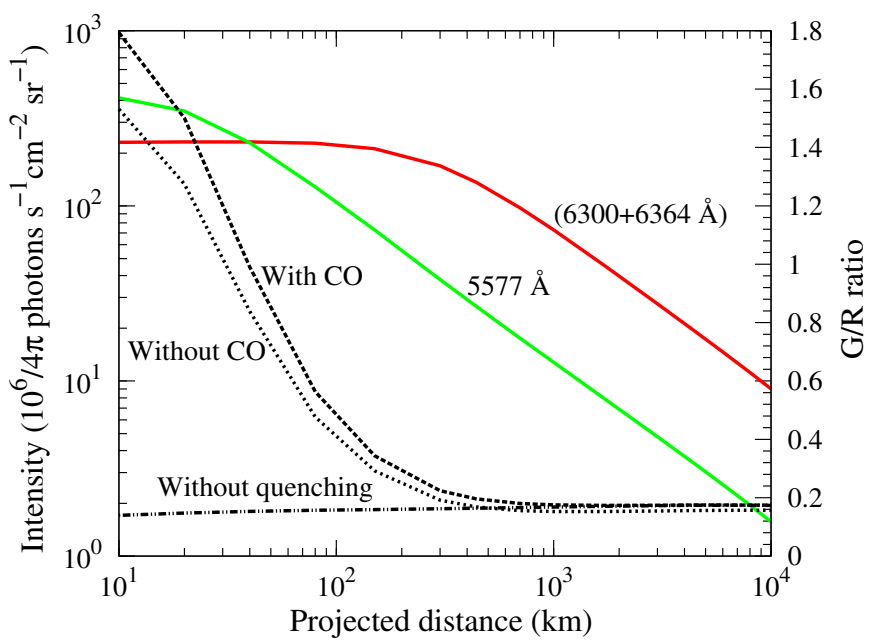

Fig. 5. Calculated [OI] red-doublet $(6300+6364 \AA)$ and $5577 \AA$ line brightness profiles (with solid curves) along the cometocentric projected distances on comet $\mathrm{C} / 2006 \mathrm{~W} 3$ (Christensen) with $\mathrm{H}_{2} \mathrm{O}$ production rate of $2 \times 10^{28} \mathrm{~s}^{-1}$ and $42 \% \mathrm{CO}_{2}$ and $98 \% \mathrm{CO}$ relative abundances with respect to $\mathrm{H}_{2} \mathrm{O}$ in the cometary coma when the comet was at 3.13 au from the Sun. The calculated $\mathrm{G} / \mathrm{R}$ ratio profiles considering $\mathrm{CO}$, without considering $\mathrm{CO}$, and without quenching are plotted with dashed, dotted, and dash-dotted curves, respectively, on the right $y$-axis.

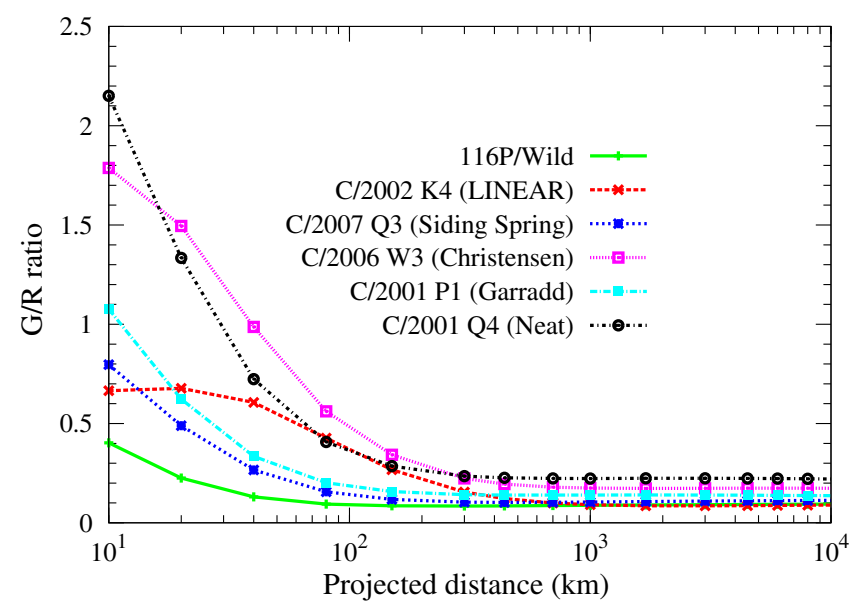

Fig. 6. Calculated radial profiles of the G/R ratio in different comets. The input parameters used to calculate the $G / R$ ratio are tabulated in Table 1. It can be seen that in comets C/2006 W3 and C/2001 Q4, due to substantial collisional quenching of $\mathrm{O}\left({ }^{1} \mathrm{~S}\right)$ and $\mathrm{O}\left({ }^{1} \mathrm{D}\right)$ with other cometary species, the calculated $\mathrm{G} / \mathrm{R}$ ratio is more than 1 closer to the nucleus, whereas above $400 \mathrm{~km}$ projected distances it is a constant.

photodissociation of $\mathrm{H}_{2} \mathrm{O}$ and $\mathrm{CO}_{2}$ together produce $50-80 \%$ of $\mathrm{O}\left({ }^{1} \mathrm{~S}\right)$, whereas, irrespective of $\mathrm{CO}_{2}$ and $\mathrm{CO}$ relative abundances, the major $(\sim 50$ to $80 \%)$ source for the formation of $\mathrm{O}\left({ }^{1} \mathrm{D}\right)$ is photodissociation of $\mathrm{H}_{2} \mathrm{O}$ followed by radiative decay of $\mathrm{O}\left({ }^{1} \mathrm{~S}\right)$ $(10-15 \%)$. At larger projected distances $\left(>10^{3} \mathrm{~km}\right)$, dissociative recombination processes of $\mathrm{H}_{2} \mathrm{O}^{+}$and $\mathrm{CO}_{2}^{+}$ions are also important production sources of $\mathrm{O}\left({ }^{1} \mathrm{~S}\right)(30-40 \%)$ and $\mathrm{O}\left({ }^{1} \mathrm{D}\right)(\sim 20 \%)$.

The calculated percentage contributions of different production processes in the total intensity of $[\mathrm{OI}]$ emissions over the observed coma on these comets are tabulated in Table 3 . These calculations suggest that photodissociation of $\mathrm{CO}_{2}$ and $\mathrm{H}_{2} \mathrm{O}$ together contribute $50-70 \%$ to the green line emission and the remaining contribution is through dissociative recombination of $\mathrm{H}_{2} \mathrm{O}^{+}$and $\mathrm{CO}_{2}^{+}$ions. In the case of red-doublet emission, photodissociation of $\mathrm{H}_{2} \mathrm{O}$ and radiative decay of $\mathrm{O}\left({ }^{1} \mathrm{~S}\right)$ together 
Table 2. Calculated percentage contributions for major production processes of $\mathrm{O}\left({ }^{1} \mathrm{~S}\right)$ and $\mathrm{O}\left({ }^{1} \mathrm{D}\right)$ in different comets.

\begin{tabular}{|c|c|c|c|c|c|c|c|c|c|c|c|c|c|c|c|c|c|c|}
\hline \multirow{3}{*}{ Comet } & \multicolumn{18}{|c|}{ Production processes of $\mathrm{O}\left({ }^{1} \mathrm{~S}\right)$ and $\mathrm{O}\left({ }^{1} \mathrm{D}\right)$ at three cometocentric projected distances $(\mathrm{km})(\%)$} \\
\hline & \multicolumn{6}{|c|}{$\mathrm{h} v+\mathrm{H}_{2} \mathrm{O}$} & \multicolumn{3}{|c|}{$\mathrm{h} v+\mathrm{CO}$} & \multicolumn{3}{|c|}{$\mathrm{O}\left({ }^{1} \mathrm{~S}\right) \rightarrow \mathrm{O}\left({ }^{1} \mathrm{D}\right)$} & \multicolumn{3}{|c|}{$\mathrm{e}_{\mathrm{th}}^{-}+\mathrm{H}_{2} \mathrm{O}^{+}$} & \multicolumn{3}{|c|}{$\mathrm{e}_{\mathrm{th}}^{-}+\mathrm{CO}_{2}^{+}$} \\
\hline & $10^{2}$ & $10^{3}$ & $10^{4}$ & $10^{2}$ & $10^{3}$ & $10^{4}$ & $10^{2}$ & $10^{3}$ & $10^{4}$ & $10^{2}$ & $10^{3}$ & $10^{4}$ & $10^{2}$ & $10^{3}$ & $10^{4}$ & $10^{2}$ & $10^{3}$ & $10^{4}$ \\
\hline $116 \mathrm{P} /$ & $\begin{array}{c}43 \\
(83)^{*}\end{array}$ & $\begin{array}{c}33 \\
(71)\end{array}$ & $\begin{array}{c}25 \\
(59)\end{array}$ & $\begin{array}{l}33 \\
(3)\end{array}$ & $\begin{array}{l}25 \\
(2)\end{array}$ & $\begin{array}{l}20 \\
(2)\end{array}$ & $\begin{array}{c}9 \\
(0.5)\end{array}$ & $\begin{array}{c}7 \\
(0.5)\end{array}$ & $\begin{array}{c}5 \\
(0.5)\end{array}$ & (8) & $(9)$ & (9) & $\begin{array}{c}5 \\
(4)\end{array}$ & $\begin{array}{c}15 \\
(14)\end{array}$ & $\begin{array}{c}22 \\
(22)\end{array}$ & $\begin{array}{c}5 \\
(0.1)\end{array}$ & $\begin{array}{c}15 \\
(0.7)\end{array}$ & $\begin{array}{l}17 \\
(2)\end{array}$ \\
\hline C/2003 K4 (LINEAR) & $\begin{array}{c}46 \\
(88)\end{array}$ & $\begin{array}{c}42 \\
(83)\end{array}$ & $\begin{array}{c}32 \\
(71)\end{array}$ & $\begin{array}{l}35 \\
(3)\end{array}$ & $\begin{array}{l}32 \\
(3)\end{array}$ & $\begin{array}{l}25 \\
(2)\end{array}$ & $\begin{array}{l}11 \\
(1)\end{array}$ & $\begin{array}{l}11 \\
(1)\end{array}$ & $\begin{array}{c}9 \\
(1)\end{array}$ & (7) & (8) & (9) & $\begin{array}{c}1 \\
(0.5)\end{array}$ & $\begin{array}{c}4 \\
(3)\end{array}$ & $\begin{array}{c}13 \\
(13)\end{array}$ & $\begin{array}{c}1 \\
(0.5)\end{array}$ & $\begin{array}{c}5 \\
(0.5)\end{array}$ & $\begin{array}{l}14 \\
(1)\end{array}$ \\
\hline C/2007 Q3 (Siding Spring) & $\begin{array}{c}35 \\
(82)\end{array}$ & $\begin{array}{c}29 \\
(73)\end{array}$ & $\begin{array}{c}21 \\
(60)\end{array}$ & $\begin{array}{l}46 \\
(4)\end{array}$ & $\begin{array}{l}37 \\
(4)\end{array}$ & $\begin{array}{l}28 \\
(3)\end{array}$ & $\begin{array}{c}4 \\
(0.5)\end{array}$ & $\begin{array}{c}3 \\
(0.5)\end{array}$ & $\begin{array}{c}2 \\
(0.5)\end{array}$ & (9) & (10) & (11) & $\begin{array}{c}2 \\
(2)\end{array}$ & $\begin{array}{l}18 \\
(9)\end{array}$ & $\begin{array}{c}17 \\
(20)\end{array}$ & $\begin{array}{c}4 \\
(0.5)\end{array}$ & $\begin{array}{l}15 \\
(2)\end{array}$ & $\begin{array}{l}23 \\
(3)\end{array}$ \\
\hline C/2006 W3 (Chri & $\begin{array}{c}18 \\
(69)\end{array}$ & $\begin{array}{c}15 \\
(61)\end{array}$ & $\begin{array}{c}11 \\
(48)\end{array}$ & $\begin{array}{l}55 \\
(9)\end{array}$ & $\begin{array}{l}47 \\
(8)\end{array}$ & $\begin{array}{l}37 \\
(7)\end{array}$ & $\begin{array}{l}17 \\
(3)\end{array}$ & $\begin{array}{l}15 \\
(2)\end{array}$ & $\begin{array}{l}11 \\
(2)\end{array}$ & $(15)$ & (16) & $(17)$ & $\begin{array}{l}0.5 \\
(1)\end{array}$ & $\begin{array}{c}3 \\
(6)\end{array}$ & $\begin{array}{c}8 \\
(15)\end{array}$ & $\begin{array}{c}3 \\
(0.5)\end{array}$ & $\begin{array}{l}15 \\
\text { (3) }\end{array}$ & $\begin{array}{l}28 \\
(5)\end{array}$ \\
\hline C/2009 P1 (Garradd) & $\begin{array}{c}22 \\
(71)\end{array}$ & $\begin{array}{c}17 \\
(58)\end{array}$ & $\begin{array}{c}14 \\
(47)\end{array}$ & $\begin{array}{l}41 \\
(6)\end{array}$ & $\begin{array}{l}32 \\
(5)\end{array}$ & $\begin{array}{l}28 \\
(4)\end{array}$ & $\begin{array}{l}22 \\
(3)\end{array}$ & $\begin{array}{l}17 \\
(3)\end{array}$ & $\begin{array}{l}15 \\
(2)\end{array}$ & (13) & (14) & (13) & $\begin{array}{c}3 \\
(4)\end{array}$ & $\begin{array}{c}9 \\
(14)\end{array}$ & $\begin{array}{c}13 \\
(19)\end{array}$ & $\begin{array}{c}8 \\
(1)\end{array}$ & $\begin{array}{l}20 \\
(3)\end{array}$ & $\begin{array}{l}23 \\
(3)\end{array}$ \\
\hline C/2001 Q4 (NEAT) & $\begin{array}{c}11 \\
(57)\end{array}$ & $\begin{array}{c}9 \\
(47)\end{array}$ & $\begin{array}{c}7 \\
(37)\end{array}$ & $\begin{array}{c}63 \\
(13)\end{array}$ & $\begin{array}{c}50 \\
(11)\end{array}$ & $\begin{array}{l}40 \\
(9)\end{array}$ & $\begin{array}{l}11 \\
(2)\end{array}$ & $\begin{array}{c}9 \\
(2)\end{array}$ & $\begin{array}{c}7 \\
(2)\end{array}$ & (21) & $(22)$ & $(22)$ & $\begin{array}{c}1 \\
(2)\end{array}$ & $\begin{array}{c}4 \\
(8)\end{array}$ & $\begin{array}{c}6 \\
(14)\end{array}$ & $\begin{array}{c}7 \\
(1)\end{array}$ & $\begin{array}{l}23 \\
(5)\end{array}$ & $\begin{array}{l}34 \\
(8)\end{array}$ \\
\hline Comet $\mathrm{X}^{* *}$ & $\begin{array}{c}8 \\
(48)\end{array}$ & $\begin{array}{c}6 \\
(38)\end{array}$ & $\begin{array}{c}5 \\
(31)\end{array}$ & $\begin{array}{c}63 \\
(15)\end{array}$ & $\begin{array}{c}47 \\
(12)\end{array}$ & $\begin{array}{c}41 \\
(10)\end{array}$ & $\begin{array}{c}8 \\
(2)\end{array}$ & $\begin{array}{c}6 \\
(1)\end{array}$ & $\begin{array}{c}5 \\
(1)\end{array}$ & (23) & (25) & (24) & $\begin{array}{l}1 \\
\text { (3) }\end{array}$ & $\begin{array}{c}3 \\
(10)\end{array}$ & $\begin{array}{c}5 \\
(13)\end{array}$ & $\begin{array}{l}12 \\
(3)\end{array}$ & $\begin{array}{l}30 \\
(8)\end{array}$ & $\begin{array}{c}37 \\
(10)\end{array}$ \\
\hline
\end{tabular}

Notes. ${ }^{(*)}$ The values in parentheses are for $\mathrm{O}\left({ }^{1} \mathrm{D}\right) ;{ }^{(*)}$ comet $\mathrm{X}$ is a hypothetical comet similar to the observational condition of comet NEAT and having equal gas production rates of $\mathrm{H}_{2} \mathrm{O}, \mathrm{CO}_{2}$, and $\mathrm{CO} ; \mathrm{h} v=$ photon; $\mathrm{e}_{\mathrm{th}}^{-}=$thermal electron.

produce $70-90 \%$ and contributions from other sources are very small.

In the case of hypothetical comet $\mathrm{X}$ which has equal $\mathrm{H}_{2} \mathrm{O}$, $\mathrm{CO}_{2}$, and $\mathrm{CO}$, gas production rates, $\sim 80 \%$ of green line emission intensity is governed by $\mathrm{CO}_{2}$ (via photodissociation of $\mathrm{CO}_{2}$ and dissociative recombination of $\mathrm{CO}_{2}^{+}$), whereas photodissociation of $\mathrm{H}_{2} \mathrm{O}$ and $\mathrm{CO}$ together contribute around $10 \%$. Dissociative recombination of $\mathrm{CO}_{2}^{+}$is the second important source and contributes around $30 \%$ to the total green line emission. In this case around $35 \%$ of red-doublet emission is produced via $\mathrm{H}_{2} \mathrm{O}$ photodissociation. The production of $\mathrm{O}\left({ }^{1} \mathrm{D}\right)$ via $\mathrm{CO}_{2}$ photodissociation is around $10 \%$ of the total while it is $\sim 25 \%$ via radiative decay of $\mathrm{O}\left({ }^{1} \mathrm{~S}\right)$, which is also essentially produced from $\mathrm{CO}_{2}$. In this case both $\mathrm{CO}_{2}$ and $\mathrm{H}_{2} \mathrm{O}$ play equally important roles in producing red-doublet emission.

We also calculated the mean excess energy released in these photodissociative excitation reactions. The maximum excess energy in photodissociation of $\mathrm{H}_{2} \mathrm{O}$ producing $\mathrm{O}\left({ }^{1} \mathrm{~S}\right)$ by solar Ly- $\alpha$ photons is $1.27 \mathrm{eV}$, whereas the mean excess energy in the photodissociation of $\mathrm{CO}_{2}$ forming $\mathrm{O}\left({ }^{1} \mathrm{~S}\right)$ is $2.55 \mathrm{eV}$. Mean excess energies in photodissociative excitation of $\mathrm{H}_{2} \mathrm{O}, \mathrm{CO}_{2}$, and $\mathrm{CO}$ producing $\mathrm{O}\left({ }^{1} \mathrm{D}\right)$ are $2.12,4.46$, and $2.54 \mathrm{eV}$, respectively. We assumed that most of these excess energies will result in kinetic motion of daughter products. Thus, the excess velocities of $\mathrm{O}\left({ }^{1} \mathrm{~S}\right)$ in photodissociative excitation of $\mathrm{H}_{2} \mathrm{O}$ and $\mathrm{CO}_{2}$ are $1.3 \mathrm{~km} \mathrm{~s}^{-1}$ and $4.4 \mathrm{~km} \mathrm{~s}^{-1}$, respectively. Similarly, the calculated excess velocities of $\mathrm{O}\left({ }^{1} \mathrm{D}\right)$ in photodissociation of $\mathrm{H}_{2} \mathrm{O}, \mathrm{CO}_{2}$, and $\mathrm{CO}$ are $1.6,5.8$, and $3.6 \mathrm{~km} \mathrm{~s}^{-1}$, respectively.

Considering only photoreactions and using the calculated contributions of each process over the cometary coma (see Table 3) we calculated the mean excess energies of $\mathrm{O}\left({ }^{1} \mathrm{~S}\right)$ and $\mathrm{O}\left({ }^{1} \mathrm{D}\right)$. Our calculated mean velocities of $\mathrm{O}\left({ }^{1} \mathrm{~S}\right)$ and $\mathrm{O}\left({ }^{1} \mathrm{D}\right)$ atoms on these comets are tabulated in Table 3 along with the derived velocities based on the observed line widths.
In comets having large $\mathrm{CO}_{2}$ relative abundances the width of the green line, which is a function of mean $\mathrm{O}\left({ }^{1} \mathrm{~S}\right)$ velocity, is mainly determined by photodissociation of $\mathrm{CO}_{2}$. Since the mean excess energy released in photodissociation of $\mathrm{CO}_{2}$ is higher, the width of the green line would be greater compared to the red-doublet emission line width (which is mainly determined by photodissociation of $\mathrm{H}_{2} \mathrm{O}$ ). Our calculated green line widths in different comets, which are presented in Table 3 , are higher than the calculated red-doublet emission line widths, which is consistent with the observations.

Depending on the composition and activity of the nucleus, comets have different gas production rates at different heliocentric distances. In order to appraise the collisional quenching of $\mathrm{O}\left({ }^{1} \mathrm{~S}\right)$ and $\mathrm{O}\left({ }^{1} \mathrm{D}\right)$ with increase in $\mathrm{H}_{2} \mathrm{O}$ production rate, we calculated the radiative efficiencies of $\mathrm{O}\left({ }^{1} \mathrm{~S}\right)$ and $\mathrm{O}\left({ }^{1} \mathrm{D}\right)$ for different water production rates. The calculated radiative efficiency profiles are shown in Fig. 7. This calculation shows that for a given water production rate the $\mathrm{O}\left({ }^{1} \mathrm{D}\right)$ is always much more quenched than that of $\mathrm{O}\left({ }^{1} \mathrm{~S}\right)$. This is mainly because the lifetime of $\mathrm{O}\left({ }^{1} \mathrm{D}\right)(\sim 120 \mathrm{~s})$ is larger by two orders of magnitude than that of $\mathrm{O}\left({ }^{1} \mathrm{~S}\right)(\sim 0.8 \mathrm{~s})$.

Since $\mathrm{CO}_{2}$ is a potentially important source of $\mathrm{O}\left({ }^{1} \mathrm{~S}\right)$ we have also carried out model calculations of the $G / R$ ratio on different water production rates by varying its relative abundance from $0 \%$ to $100 \%$ with respect to $\mathrm{H}_{2} \mathrm{O}$. The calculations presented in Fig. 8 suggests that by increasing $\mathrm{CO}_{2}$ relative abundance in a comet the $\mathrm{G} / \mathrm{R}$ ratio increases almost monotonically.

\section{Discussion}

For comets close to 1 au from the Sun the dominant species in the cometary coma is $\mathrm{H}_{2} \mathrm{O}$. Because of lower ice-sublimation temperatures of $\mathrm{CO}$ and $\mathrm{CO}_{2}$, at large heliocentric distances the cometary coma is dominantly composed of $\mathrm{CO}_{2}$ and $\mathrm{CO}$ 
S. Raghuram and A. Bhardwaj: Atomic oxygen emission lines in comets at large heliocentric distances

Table 3. Calculated percentage contributions for major production processes of green and red-doublet emissions in the slit projected field of view on different comets, and the comparison of the calculated and observed line widths.

\begin{tabular}{|c|c|c|c|c|c|c|c|c|c|c|}
\hline \multirow[t]{2}{*}{ Comet } & \multirow[t]{2}{*}{$\mathrm{h} v+\mathrm{H}_{2} \mathrm{O}$} & \multirow[t]{2}{*}{$\mathrm{h} v+\mathrm{CO}_{2}$} & \multirow[t]{2}{*}{$\mathrm{h} v+\mathrm{CO}$} & \multirow[t]{2}{*}{$\mathrm{O}\left({ }^{1} \mathrm{~S}\right) \rightarrow \mathrm{O}\left({ }^{1} \mathrm{D}\right)$} & \multirow[t]{2}{*}{$\mathrm{e}_{\mathrm{th}}^{-}+\mathrm{H}_{2} \mathrm{O}^{+}$} & \multirow[t]{2}{*}{$\mathrm{e}_{\mathrm{th}}^{-}+\mathrm{CO}_{2}^{+}$} & \multicolumn{2}{|c|}{5577 Line width } & \multicolumn{2}{|c|}{6300 Line width } \\
\hline & & & & & & & $\mathrm{Cal}^{* * *}$ & $\mathrm{Obs}^{* *}$ & $\mathrm{Cal}^{* * *}$ & $\mathrm{Obs}^{* *}$ \\
\hline 116P/Wild 4 & $34(72)^{*}$ & $26(2)$ & $7(0.5)$ & (9) & $14(13)$ & $14(1)$ & 1.70 & - & 1.32 & - \\
\hline C/2003 K4 (LINEAR) & $40(81)$ & $31(3)$ & $10(1)$ & (8) & $6(5)$ & $7(0.5)$ & 2.05 & $2.38-2.76$ & 1.87 & $1.81-2.12$ \\
\hline C/2007 Q3 (Siding Spring) & $28(72)$ & $37(4)$ & $3(0.5)$ & (10) & $9(10)$ & $15(1)$ & 2.04 & - & 1.44 & - \\
\hline C/2006 W3 (Christensen) & $14(61)$ & $47(8)$ & $14(3)$ & (16) & $3(6)$ & $15(3)$ & 2.48 & - & 1.58 & - \\
\hline C/2009 P1 (Garradd) & $16(55)$ & $31(4)$ & $17(3)$ & (13) & $10(15)$ & $21(3)$ & 1.85 & $2.16-2.54$ & 1.25 & $1.25-1.67$ \\
\hline C/2001 Q4 (NEAT) & $8(44)$ & $47(11)$ & $8(2)$ & (22) & $4(9)$ & $26(6)$ & 2.30 & $2.31-2.55$ & 1.65 & $2.39-2.75$ \\
\hline Comet $\mathrm{X}^{* * * *}$ & $6(36)$ & $46(11)$ & $6(1)$ & (25) & $4(10)$ & $31(8)$ & 2.35 & - & 1.65 & - \\
\hline
\end{tabular}

Notes. ${ }^{(*)}$ The values in parentheses are calculated percentage contributions for red-doublet emission; ${ }^{(* *)}$ Obs: observed line widths are taken from Decock et al. (2013); ${ }^{(* *)} \mathrm{Cal}$ : model calculated line widths; ${ }^{(* * *)}$ comet $\mathrm{X}$ is a hypothetical comet similar to the observational condition of comet NEAT and having equal gas production rates of $\mathrm{H}_{2} \mathrm{O}, \mathrm{CO}_{2}$, and $\mathrm{CO} ; \mathrm{h} v=$ photon; $\mathrm{e}_{\text {th }}^{-}=$thermal electron.

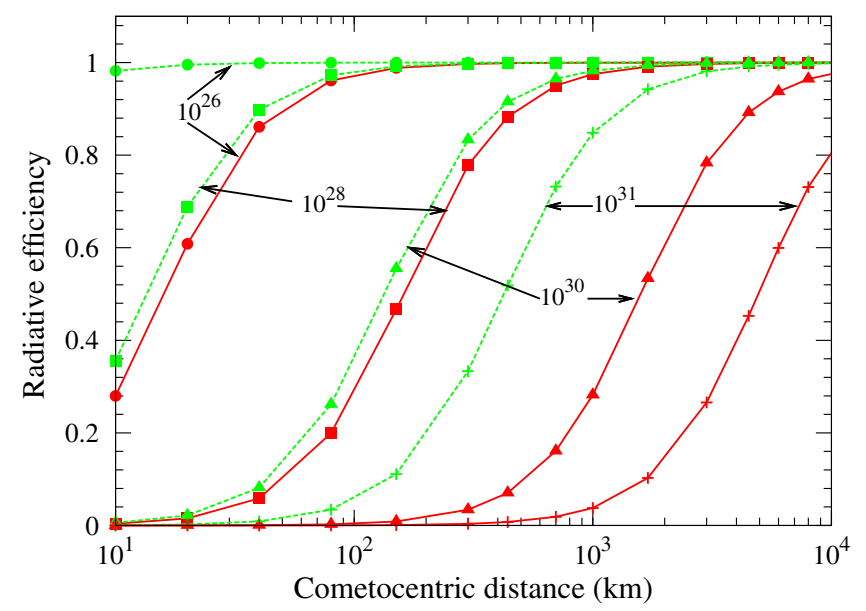

Fig. 7. Calculated radiative efficiency profiles of $\mathrm{O}\left({ }^{1} \mathrm{~S}\right)$ (green lines) and $\mathrm{O}\left({ }^{1} \mathrm{D}\right)$ (red lines) for different production rates with $5 \% \mathrm{CO}_{2}$ and $10 \%$ $\mathrm{CO}$ relative abundances with respect to $\mathrm{H}_{2} \mathrm{O}$. The circles, squares, triangles, and cross symbols represent the calculated radiative efficiencies for the water production rates of $10^{26}, 10^{28}, 10^{30}$, and $10^{31}$, respectively.

(Meech \& Svoreň 2004; Crovisier et al. 1999; Biver et al. 1997, 1999; Bockelée-Morvan et al. 2004, 2010). Owing to strong absorption of cometary $\mathrm{H}_{2} \mathrm{O}$ infrared emission lines by terrestrial water molecules, it is difficult to detect $\mathrm{H}_{2} \mathrm{O}$ in the coma for ground-based observations, but the spatial profiles of water can be easily derived in comets from ground-based observatories by observing infrared $\mathrm{H}_{2} \mathrm{O}$ non-resonance fluorescence emissions (Mumma et al. 1995, 1996; Dello Russo et al. 2000). Since $\mathrm{H}_{2} \mathrm{O}$ does not have any transitions in the visible region the emissions of its daughter products have been used as tracers to understand the spatial distribution of water in the cometary coma. The observed atomic oxygen visible emissions (viz. O[I] 5577, 6300, and $6364 \AA$ ) have been used to quantify the $\mathrm{H}_{2} \mathrm{O}$ production rate in several comets around 1 au (Delsemme \& Combi 1976, 1979; Fink \& Johnson 1984; Schultz et al. 1992; Morgenthaler et al. 2001). Since $\mathrm{CO}_{2}$ and $\mathrm{CO}$ can also produce these metastable oxygen atoms, based on the theoretical work of Festou \& Feldman (1981), the G/R ratio of 0.1 has been used as the benchmark to confirm $\mathrm{H}_{2} \mathrm{O}$ as the parent species for these oxygen emission lines. The available theoretical and experimental cross sections for the production of $\mathrm{O}\left({ }^{1} \mathrm{~S}\right)$ and $\mathrm{O}\left({ }^{1} \mathrm{D}\right)$ from different O-bearing species have been

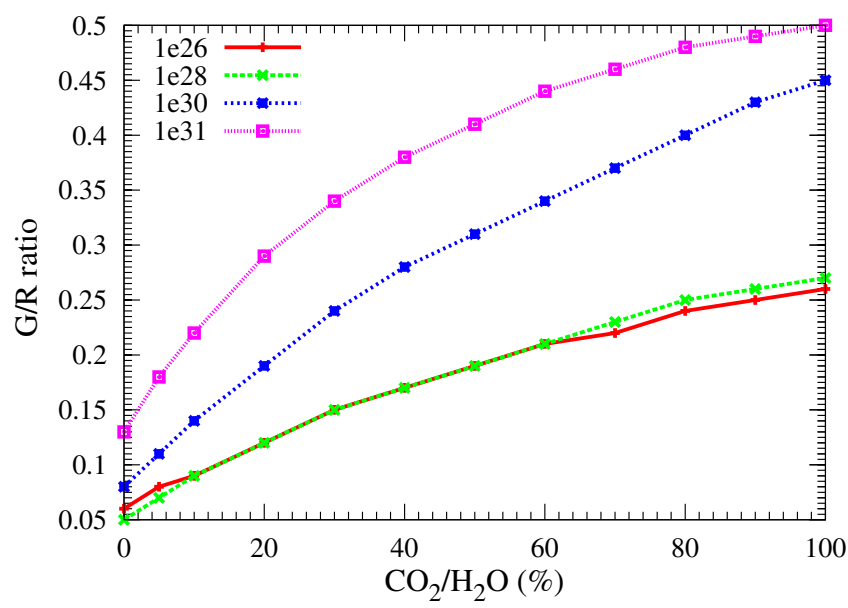

Fig. 8. Calculated G/R ratio as a function of $\mathrm{CO}_{2}$ abundance for different water production rates, with $10 \% \mathrm{CO}$ abundance relative to $\mathrm{H}_{2} \mathrm{O}$ in the coma. These calculations are done at heliocentric and geocentric distances of 1 au using a square slit of side $5^{\prime \prime}$.

reviewed in our previous work (Bhardwaj \& Raghuram 2012). Our coupled chemistry-emission model, which has been applied to comets Hyakutake and Hale-Bopp, suggested that the observed $\mathrm{G} / \mathrm{R}$ ratio not only depends on the relative abundances of $\mathrm{CO}_{2}$ and $\mathrm{CO}$, but also on the projected area observed on the comet (Bhardwaj \& Raghuram 2012).

Since $\mathrm{CO}_{2}$ does not emit ultraviolet or visible photons we cannot detect this molecule directly in the cometary ultraviolet or visible spectra. Moreover, $\mathrm{CO}_{2}$ is a symmetric molecule with no permanent dipole moment and so it is difficult to observe this molecule even in radio range from the ground (Ootsubo et al. 2012). Thus, this molecule is probed using indirect methods using the emissions of its dissociative products, like the CO Cameron band $\left(\mathrm{a}^{3} \Pi-\mathrm{X}^{1} \Sigma^{+}\right)$in ultraviolet (Weaver et al. 1994; Feldman et al. 1997) and visible atomic oxygen green and red-doublet emissions (Furusho et al. 2006; McKay et al. 2012; Decock et al. 2013). Our earlier works (Bhardwaj \& Raghuram 2011; Raghuram \& Bhardwaj 2012) have shown that $\mathrm{CO}$ Cameron band emission is not suitable for measuring $\mathrm{CO}_{2}$ abundances in comets since this emission is mainly governed by photoelectron impact excitation of $\mathrm{CO}$ rather than the photodissociation of $\mathrm{CO}_{2}$. 
Assuming that the green line emission is governed by photodissociation of $\mathrm{CO}_{2}$ while the red-doublet emission is controlled by photodissociation of $\mathrm{H}_{2} \mathrm{O}$, the observed $\mathrm{G} / \mathrm{R}$ ratio has been used to quantify $\mathrm{CO}_{2}$ relative abundance in the comets (McKay et al. 2012; Decock et al. 2013). At larger heliocentric distances $\mathrm{CO}_{2}$ and $\mathrm{CO}$ are the dominant $\mathrm{O}$-bearing species in the coma which can produce green and red-doublet emissions. In several comets the observed $\mathrm{G} / \mathrm{R}$ ratio at large ( $>2 \mathrm{au}$ ) heliocentric distances is more than 0.1 (Decock et al. 2013; McKay et al. 2012; Furusho et al. 2006).

\subsection{Impact of $\mathrm{CO}$ on the $\mathrm{G} / \mathrm{R}$ ratio}

At larger heliocentric distances, although $\mathrm{CO}$ abundance is substantial in the cometary comae, the photodissociation of $\mathrm{CO}$ is not a potential source of $\mathrm{O}\left({ }^{1} \mathrm{~S}\right)$ and $\mathrm{O}\left({ }^{1} \mathrm{D}\right)$ atoms. This is mainly due to the proximity in the threshold energies of photodissociative excitation and photoionization of $\mathrm{CO}$ molecules. The threshold energies for dissociation of $\mathrm{CO}$ into $\mathrm{O}\left({ }^{1} \mathrm{D}\right)$ and $\mathrm{O}\left({ }^{1} \mathrm{~S}\right)$ states are 14.35 and $16.58 \mathrm{eV}$, respectively, whereas it is $14 \mathrm{eV}$ for ionization. Moreover, the branching ratio of ionization for the photons having energy more than $14 \mathrm{eV}$ is $\sim 0.98$ (Huebner et al. 1992). Since the ionization energy is smaller than energy required in the formation of $\mathrm{O}\left({ }^{1} \mathrm{~S}\right)$ and $\mathrm{O}\left({ }^{1} \mathrm{D}\right)$, most of the photons $(>90 \%)$ having energy $>14 \mathrm{eV}$ ionize the $\mathrm{CO}$ molecule rather than causing photodissociative excitation. Based on Huebner \& Carpenter (1979) compiled cross sections, Festou \& Feldman (1981) estimated that the photodissociation of $\mathrm{CO}$ produces $\mathrm{O}\left({ }^{1} \mathrm{~S}\right)$ and $\mathrm{O}\left({ }^{1} \mathrm{D}\right)$ with nearly equal rates. To evaluate the role of $\mathrm{CO}$ we also did calculations in comet $\mathrm{C} / 2006 \mathrm{~W} 3$ by discarding photodissociation of $\mathrm{CO}$ as a source mechanism of both $\mathrm{O}\left({ }^{1} \mathrm{~S}\right)$ and $\mathrm{O}\left({ }^{1} \mathrm{D}\right)$ (see Fig. 5). Though $\mathrm{CO}$ production rate is equal to that of $\mathrm{H}_{2} \mathrm{O}$ in this comet (see Table 1), by removing $\mathrm{CO}$ contribution the calculated $\mathrm{G} / \mathrm{R}$ ratio decreased by a maximum of about $10 \%$. Similarly, our calculated percentage contribution over the observed coma on different comets, which is presented in Table 3, also suggests that the role of $\mathrm{CO}$ is very small $(<20 \%)$ in producing $\mathrm{O}\left({ }^{1} \mathrm{~S}\right)$ and $\mathrm{O}\left({ }^{1} \mathrm{D}\right)$ atoms and subsequently in determining the red-doublet emission intensity. Even without considering photodissociation of $\mathrm{CO}$ in the model the calculated $\mathrm{G} / \mathrm{R}$ ratio values are in agreement with the observations. Based on these calculations we can suggest that the photodissociation of $\mathrm{CO}$ is an insignificant source of $\mathrm{O}\left({ }^{1} \mathrm{~S}\right)$ and $\mathrm{O}\left({ }^{1} \mathrm{D}\right)$. Hence, the photodissociation of $\mathrm{CO}$ has almost no impact on the $\mathrm{G} / \mathrm{R}$ ratio.

\subsection{Impact of $\mathrm{CO}_{2}$ on the $\mathrm{G} / \mathrm{R}$ ratio}

The relative abundance of $\mathrm{CO}_{2}$ with respect to $\mathrm{H}_{2} \mathrm{O}$, is very important in determining the $\mathrm{G} / \mathrm{R}$ ratio. This can be understood from the calculated $\mathrm{G} / \mathrm{R}$ ratio profiles on comets $116 \mathrm{P}$, $\mathrm{C} / 2007 \mathrm{Q} 3$, and $\mathrm{C} / 2001 \mathrm{Q} 4$, which have nearly same $\mathrm{H}_{2} \mathrm{O}$ production rates $\left(1-4 \times 10^{28} \mathrm{~s}^{-1}\right)$, but different relative abundances of $\mathrm{CO}_{2}$ and $\mathrm{CO}$, and are observed at different heliocentric distances (see Fig. 6). As discussed in Sect. 4.1, the CO abundance does not have any appreciable impact on the $G / R$ ratio. Hence, the change in the calculated $G / R$ ratio on these comets can be ascribed mainly to the difference in $\mathrm{CO}_{2}$ relative abundances. The calculated $\mathrm{G} / \mathrm{R}$ ratio profiles on these comets are shown in Fig. 6, which shows that by increasing $\mathrm{CO}_{2}$ the $\mathrm{G} / \mathrm{R}$ ratio increases. In comet $\mathrm{C} / 2001 \mathrm{Q} 4$, due to higher $(75 \%) \mathrm{CO}_{2}$ relative abundance, the calculated $\mathrm{G} / \mathrm{R}$ ratio value is more than one close to the cometary nucleus. Similar behaviour is seen for comet $\mathrm{C} / 2006 \mathrm{~W} 3$ which is due to larger $(\sim 40 \%) \mathrm{CO}_{2}$ relative abundance with respect to $\mathrm{H}_{2} \mathrm{O}$, and also due to significant collisional quenching of $\mathrm{O}\left({ }^{1} \mathrm{D}\right)$ (see Fig. 5). We found that by doubling $\mathrm{CO}_{2}$ relative abundance the $\mathrm{G} / \mathrm{R}$ ratio changes by $\sim 25 \%$, whereas collisional quenching alone can vary its value by an order of magnitude. The model calculated $G / R$ ratio values in comets 116P, C/2007 Q3, and C/2009 P1 are smaller by a factor of around 1.5 compared to the observations.

The detection of $\mathrm{CO}_{2}$ molecules in the coma has been carried out using several infrared satellites by observing its fundamental vibrational band emission $\left(v_{3}\right)$ at $4.26 \mu \mathrm{m}$ (Crovisier et al. 1996, 1997, 1999; Colangeli et al. 1999; Reach et al. 2010; Ootsubo et al. 2012). The quantification of $\mathrm{CO}_{2}$ abundance based on the observed infrared emission intensity is subjected to opacity of the cometary coma. Since the $\mathrm{CO}_{2}$ fluorescence efficiency factor ( $g$-factor) is larger compared to that of $\mathrm{H}_{2} \mathrm{O}$ and $\mathrm{CO}$ (see Table 2 of Ootsubo et al. 2012), these emission lines are optically thick in the inner coma, which can result in underestimation of $\mathrm{CO}_{2}$ abundance if proper treatment of radiative transfer is not accounted for in the analysis. The optical depth effects in the inner coma may cause the surface brightness profile of these emissions to be much flatter and resemble the presence of extended sources in the coma. In comet Hale-Bopp, Bockelée-Morvan et al. (2010) have shown that the observed broad extent of infrared $\mathrm{CO}$ brightness is due to optical depth effects of the emitted radiation and not because of extended sources. Since these comets are observed at larger heliocentric distances and have low gas production rates, the collision dominated coma size is only a few hundred kilometers. Thus, the opacity effects of these IR emissions can be significant close to the nucleus and can influence the derivation of $\mathrm{CO}_{2}$ production rate based on the observed flux over the field of view. The discrepancies between the Ootsubo et al. (2012) derived production rates and other observations might be due to opacity of the cometary comae or may be due to assumed input parameters in the derivation of gas production rates. Under assumed optically thin condition the Ootsubo et al. (2012) derived gas production rates in several comets can be regarded as lower limits. Considering these observational facts we varied $\mathrm{CO}_{2}$ abundances in the model to assess our model calculated $\mathrm{G} / \mathrm{R}$ ratio with the observations. By increasing $\mathrm{CO}_{2}$ abundances in these comets by a factor of 3 we could achieve better agreement with the observed $\mathrm{G} / \mathrm{R}$ ratio.

Similarly, the calculations presented in Fig. 8 demonstrate that for a constant $\mathrm{H}_{2} \mathrm{O}$ production rate, the $\mathrm{G} / \mathrm{R}$ ratio increases with increasing $\mathrm{CO}_{2}$ relative abundance. This figure suggests that for a constant $\mathrm{CO}_{2}$ relative abundance, by increasing the $\mathrm{H}_{2} \mathrm{O}$ production rate, the collisional quenching of $\mathrm{O}\left({ }^{1} \mathrm{~S}\right)$ and $\mathrm{O}\left({ }^{1} \mathrm{D}\right)$ can increase the $\mathrm{G} / \mathrm{R}$ ratio. Thus, the observation of a larger $\mathrm{G} / \mathrm{R}$ ratio value need not be always due to higher $\mathrm{CO}_{2}$ abundances.

In the case of hypothetical comet $\mathrm{X}$, which has $\mathrm{CO}_{2}$ abundance equal to that of $\mathrm{H}_{2} \mathrm{O}$, the calculated percentage contributions of different processes to red-doublet emissions presented in Table 3 suggest that the red-doublet emission intensity is equally controlled by $\mathrm{CO}_{2}$ and $\mathrm{H}_{2} \mathrm{O}$. If a comet has equal abundances of $\mathrm{CO}_{2}$ and $\mathrm{H}_{2} \mathrm{O}$, which is the case for comet $\mathrm{C} / 2006 \mathrm{~W} 3 \mathrm{ob}-$ served by Ootsubo et al. (2012) at 3.7 au from the Sun, deriving the water production rates based on the observed red-doublet emission intensity may result in over estimation of $\mathrm{H}_{2} \mathrm{O}$. In this case the derivation of $\mathrm{CO}_{2}$ abundances using the observed $\mathrm{G} / \mathrm{R}$ ratio also leads to improper estimation. This calculation suggests that in a comet having high $\mathrm{CO}_{2}$ abundance, the red-doublet emission intensity is not suitable for measuring $\mathrm{H}_{2} \mathrm{O}$ rates. Similarly, our model calculations on comet C/2001 Q4, which has $75 \% \mathrm{CO}_{2}$ relative abundance, suggest that around $30 \%$ of 
red-doublet emissions are governed by both photodissociation of $\mathrm{CO}_{2}$ and radiative decay of $\mathrm{O}\left({ }^{1} \mathrm{~S}\right)$, which is comparable to the contribution from $\mathrm{H}_{2} \mathrm{O}(\sim 45 \%)$ (see Table 3).

\subsection{Impact of collisional quenching of $O(S)$ and $O(D)$ on the $G / R$ ratio}

The $\mathrm{G} / \mathrm{R}$ ratio at a given projected distance mainly depends on the formation and destruction processes of excited oxygen atoms in the cometary coma along the line of sight. The abundances of O-bearing species and solar flux governs the formation rate of these metastable species while the chemical lifetime and collisional quenching by other cometary species determines the destruction rate. In a comet having moderate $\mathrm{H}_{2} \mathrm{O}$ production rate of $4 \times 10^{28} \mathrm{~s}^{-1}$, the radius of the $\mathrm{H}_{2} \mathrm{O}$ collisional zone is around $1000 \mathrm{~km}$ (Whipple \& Huebner 1976). When the comet is at a larger heliocentric distance, a lower gas evaporation rate results in a smaller collisional coma. Discarding the collisional quenching effect the observed $\mathrm{G} / \mathrm{R}$ ratio has been used to infer $\mathrm{CO}_{2}$ production rate in comets observed at large heliocentric distances (McKay et al. 2012; Decock et al. 2013). Our calculated G/R ratio values as a function of projected distance on different comets (cf. Figs. 5 and 6) have shown that the collisional quenching of $\mathrm{O}\left({ }^{1} \mathrm{~S}\right)$ and $\mathrm{O}\left({ }^{1} \mathrm{D}\right)$ can result in larger (even $\left.>1\right) \mathrm{G} / \mathrm{R}$ ratio values. Since the $\mathrm{G} / \mathrm{R}$ ratio is averaged over the observed large projected distances, the collisional quenching may not influence the average value. In this case the observed $\mathrm{G} / \mathrm{R}$ ratio is mainly determined by photochemical reactions of $\mathrm{H}_{2} \mathrm{O}$ and $\mathrm{CO}_{2}$ in producing red and green emissions, respectively. Hence, the observed G/R ratio value can be used to estimate the upper limit of $\mathrm{CO}_{2}$ abundance relative to the $\mathrm{H}_{2} \mathrm{O}$ production rate. But in the case of observations over smaller projected distances the collisional zone can predominantly affect the observed $G / R$ ratio value which eventually can lead to the estimation of higher $\mathrm{CO}_{2}$ abundances. Since the comets considered in this study are observed over large projected distances the effect of collisional quenching is small on the averaged $\mathrm{G} / \mathrm{R}$ ratio. In such cases the observed $\mathrm{G} / \mathrm{R}$ ratio value can be effective in constraining the upper limit of the $\mathrm{CO}_{2}$ relative abundance.

\subsection{Green and red-doublet emission line widths}

Cochran (2008) made high-resolution observations on different comets and found that the green line width is higher than both red-doublet emission lines. The observation of these forbidden lines made on 12 comets have also shown the same feature (Decock et al. 2013). The wider green line implies higher mean velocity distribution of $\mathrm{O}\left({ }^{1} \mathrm{~S}\right)$ atoms in the cometary coma. The high velocity of $\mathrm{O}\left({ }^{1} \mathrm{~S}\right)$ atoms in the cometary coma could be due to a parent source other than $\mathrm{H}_{2} \mathrm{O}$ or could be due to involvement of high energy photons in $\mathrm{H}_{2} \mathrm{O}$ dissociation. Our model calculations on comet Hale-Bopp showed that $\mathrm{CO}_{2}$ photodissociation is a potentially more important source than that of $\mathrm{H}_{2} \mathrm{O}$ in producing $\mathrm{O}\left({ }^{1} \mathrm{~S}\right)$ atoms with high excess velocity (Raghuram \& Bhardwaj 2013).

From the calculations presented in Table 3, it can be understood that both $\mathrm{CO}_{2}$ and $\mathrm{H}_{2} \mathrm{O}$ are the important sources of $\mathrm{O}\left({ }^{1} \mathrm{~S}\right)$, whereas $\mathrm{O}\left({ }^{1} \mathrm{D}\right)$ is mainly sourced from $\mathrm{H}_{2} \mathrm{O}$. Since high energy photons (955-1165 $\AA$ ) mainly dissociate $\mathrm{CO}_{2}$ and produce $\mathrm{O}\left({ }^{1} \mathrm{~S}\right)$, the mean excess energy released in this reaction is larger $(\sim 2.5 \mathrm{eV})$ compared to that of $\mathrm{H}_{2} \mathrm{O}(\sim 1.2 \mathrm{eV})$. This results in the production of $\mathrm{O}\left({ }^{1} \mathrm{~S}\right)$ atoms with large velocities $\left(4.3 \mathrm{~km} \mathrm{~s}^{-1}\right)$ in cometary coma. The calculations presented in Table 3 show that above $10^{4} \mathrm{~km}$ projected distances, the thermal recombination of $\mathrm{H}_{2} \mathrm{O}^{+}$and $\mathrm{CO}_{2}^{+}$ions together results in the production of $15-40 \%$ of $\mathrm{O}\left({ }^{1} \mathrm{~S}\right)$ and around $20 \%$ of $\mathrm{O}\left({ }^{1} \mathrm{D}\right)$. Rosén et al. (2000) and Seiersen et al. (2003) experimentally determined the excess energies and branching ratios for the dissociative products in dissociative recombination of $\mathrm{H}_{2} \mathrm{O}^{+}$and $\mathrm{CO}_{2}^{+}$ions, respectively. Based on these measured branching fractions and by theoretical estimation, we calculated the excess velocities of $\mathrm{O}\left({ }^{1} \mathrm{~S}\right)$ and $\mathrm{O}\left({ }^{1} \mathrm{D}\right)$ and green and red line widths by incorporating the dissociative recombination reactions. We found an increase in our calculated green and red line widths by a factor of 1.2-1.7 and 1.1-2.2, respectively. However, without accounting for dissociative recombination reactions in our model, the calculated $G / R$ ratio values (see Table 1) and line widths (see Table 3 ) are consistent with the observations. In comet C/2001 Q4 our calculated red line width is smaller than the observed value. It can be noticed that in this comet both green and red-doublet line widths are nearly the same and the red line widths are higher compared to those on other comets, which is difficult to explain based on the model calculations.

Our calculations show that the dissociative recombination of $\mathrm{H}_{2} \mathrm{O}^{+}$and $\mathrm{CO}_{2}^{+}$ions are an important source of $\mathrm{O}\left({ }^{1} \mathrm{~S}\right)$ in the outer coma. In the model calculations we assumed a constant electronion recombination temperature of $300 \mathrm{~K}$. Since comets are observed at large heliocentric distances the temperature values can be less than $300 \mathrm{~K}$. To study the effect of electron temperature on the calculated $\mathrm{G} / \mathrm{R}$ ratio and line widths we decreased the temperature to $200 \mathrm{~K}$. We did not find any noticeable change in the calculated $\mathrm{G} / \mathrm{R}$ ratio values or line widths. Since most of the green and red-doublet emission intensities are determined by photodissociation reactions in the inner coma the contribution of thermal recombination of ions on the averaged $\mathrm{G} / \mathrm{R}$ ratio is rather small.

Several observations beyond 2 au have shown that the $\mathrm{H}_{2} \mathrm{O}$ production rate in comets does not vary as a function of the inverse square of heliocentric distance (Biver et al. 1997, 1999, 2007; Bodewits et al. 2012). Hence, extrapolation of the $\mathrm{H}_{2} \mathrm{O}$ production rate based on an approximation of the inverse square of heliocentric distance may be inappropriate. We evaluated the implications of this extrapolation in comet C/2003 K4 by decreasing the $\mathrm{H}_{2} \mathrm{O}$ production rate by a factor of 2 . No significant change (decrease by $\leq 5 \%$ ) is observed in the model calculated $\mathrm{G} / \mathrm{R}$ ratio and the calculated line widths.

\subsection{Effect of atmospheric seeing}

For small (0.6-2") slit observations the differential atmospheric seeing can be an issue while determining the $G / R$ ratio based on the observed atomic oxygen green and red-doublet line emission fluxes. The work carried out by McKay et al. (2014) suggests that the differential refraction is potentially important for the near UV (e.g. CN $3870 \AA$ ) compared to the observation in the wavelength region 5000-6500 $\AA$. They calculated the effect of differential refraction to be around $5 \%$ or less. In order to estimate the atmospheric seeing effect in determining slit-averaged $\mathrm{G} / \mathrm{R}$ ratio we convolved our model calculated green and reddoublet emission fluxes with Gaussian function with full width at half maximum of seeing value $1.0^{\prime \prime}$. All these comets, except $116 \mathrm{P}$, considered in the present work have been observed at larger ( $>2 \mathrm{au})$ geocentric distances; hence, the projected area on these comets would be larger.

In comet $\mathrm{C} / 2001 \mathrm{Q} 4$, which was observed at $r=3.7$ au and $\Delta=3.4 \mathrm{au}$, the model calculated $\mathrm{G} / \mathrm{R}$ ratio varies between 2.2 


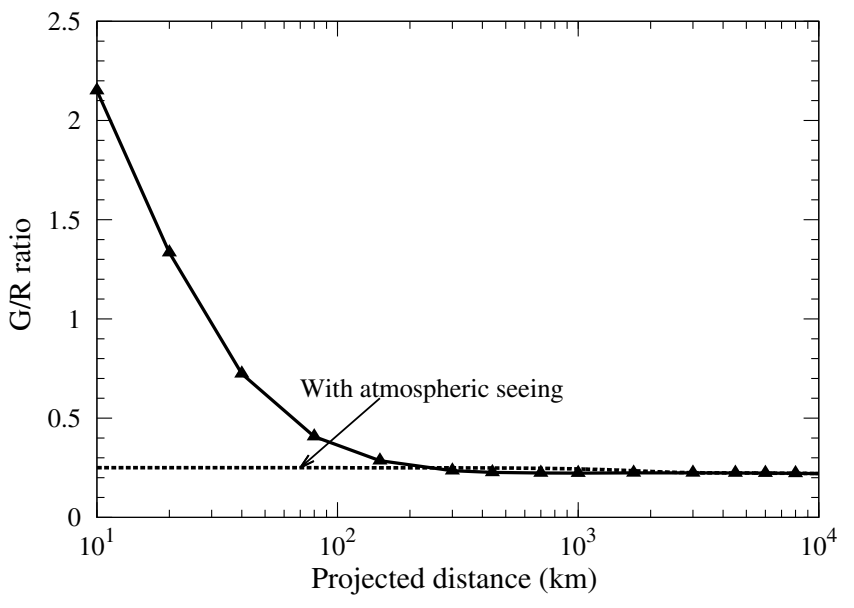

Fig. 9. Model calculated G/R ratio on comet C/2001 Q4 (NEAT) at $r=$ $3.7 \mathrm{au}$ and $\Delta=3.4 \mathrm{au}$. The black dashed line is the calculated $\mathrm{G} / \mathrm{R}$ ratio after convolving with a Gaussian function of full width at half maximum of $1.0^{\prime \prime}$ seeing value.

and 0.2 below $100 \mathrm{~km}$ projected distance (cf. Figs. 6 and 9). After incorporating the seeing effect we found that the calculated $\mathrm{G} / \mathrm{R}$ ratio is a constant throughout the projected distances with a value of about 0.2 as shown in Fig. 9. However, we do not find any change in the slit-averaged $G / R$ ratio after accounting for the seeing effect in the model. Since the slit-averaged G/R ratio is over a much larger projected area, while the seeing effect is confined to distances close to the nucleus (cf. Fig. 6). We also assessed the output by changing the seeing value (from 1.0" to $\left.0.5^{\prime \prime}\right)$. No appreciable change in the modelled G/R ratio is observed. This suggests that the atmospheric seeing effect does not influence the $\mathrm{G} / \mathrm{R}$ ratio for the comets observed at larger ( $>2 \mathrm{au}$ ) geocentric distances. Detailed analysis of the atmospheric seeing on different comets observed at different geocentric distances $(<2 \mathrm{au})$ are being carried out and will be presented in our next paper (Decock et al. 2014, in prep.).

\section{Summary and conclusion}

The observation of green and red-doublet emission lines in comets at larger ( $>2 \mathrm{au}$ ) heliocentric distances suggest that the $\mathrm{G} / \mathrm{R}$ ratio value is larger than 0.1 . Moreover, the highresolution observation reports that the green line is wider than the red-doublet lines, which is difficult to explain based on the single parent source for these oxygen emission lines (Decock et al. 2013). We have developed a coupled chemistry-emission model for atomic oxygen visible prompt emissions and applied it on six comets, (viz. 116P/Wild 4, C/2003 K4 (LINEAR), C/2007 Q3 (Siding Spring), C/2006 W3 (Christensen), C/2009 P1 (Garradd), C/2001 Q4 (NEAT)) which are observed at heliocentric distances greater than 2 au. By accounting for important chemical reactions in the model we calculated the $\mathrm{G} / \mathrm{R}$ ratio values and widths of green and red-doublet emission lines on these comets. It is found that $\mathrm{CO}_{2}$ is potentially more important than $\mathrm{H}_{2} \mathrm{O}$ in $\mathrm{O}\left({ }^{1} \mathrm{~S}\right)$ production while $\mathrm{O}\left({ }^{1} \mathrm{D}\right)$ is mainly controlled by $\mathrm{H}_{2} \mathrm{O}$. The photodissociation of $\mathrm{CO}$ is an insignificant source of metastable oxygen atoms. The observed large green line width in several comets is due to higher velocity of $\mathrm{O}\left({ }^{1} \mathrm{~S}\right)$ atoms that are essentially produced via photodissociation of $\mathrm{CO}_{2}$ by higher energy (955-1165 $\AA$ ) photons. We have shown that the collisional quenching of $\mathrm{O}\left({ }^{1} \mathrm{~S}\right)$ and $\mathrm{O}\left({ }^{1} \mathrm{D}\right)$ by $\mathrm{H}_{2} \mathrm{O}$ can lead to a larger $\mathrm{G} / \mathrm{R}$ ratio value and that its impact on the
$\mathrm{G} / \mathrm{R}$ ratio is larger than the change in $\mathrm{CO}_{2}$ relative abundance. Hence, the larger $\mathrm{G} / \mathrm{R}$ ratio value need not always be linked to larger $\mathrm{CO}_{2}$ abundances. In a comet having large $(>50 \%) \mathrm{CO}_{2}$ abundances, the photodissociation of $\mathrm{CO}_{2}$ plays a significant role in producing both green and red-doublet emissions; thus, this process should also be accounted for while deriving the $\mathrm{H}_{2} \mathrm{O}$ production rate based on the red-doublet emission intensity. When a comet is observed over a larger projected distance where the collisional zone is less resolvable, the collisional quenching does not affect the observed $\mathrm{G} / \mathrm{R}$ ratio. At larger heliocentric distances, due to smaller gas production rates, the radius of a collisional coma is smaller; hence, the $\mathrm{G} / \mathrm{R}$ ratio observed over larger projected distances can be used to constrain the $\mathrm{CO}_{2}$ relative abundance. However, if the slit-projected area on the comet is smaller (with respect to the collisional zone), the derived $\mathrm{CO}_{2}$ abundance based on the $\mathrm{G} / \mathrm{R}$ ratio would be overestimated. Our model calculated $\mathrm{G} / \mathrm{R}$ ratio and line widths of green and red-doublet emission are in agreement with the observation.

Acknowledgements. S. Raghuram was supported by the ISRO Senior Research Fellowship during the period of this work. Solar Irradiance Platform historical irradiances are provided courtesy of W. Kent Tobiska and Space Environment Technologies. These historical irradiances have been developed with partial funding from the NASA UARS, TIMED, and SOHO missions. We thank Alice Decock, Jeffrey P. Morgenthaler, and Adam McKay for the helpful discussions on the seeing effect on observation of comets.

\section{References}

Bhardwaj, A. 1999, J. Geophys. Res., 104, 1929

Bhardwaj, A., \& Haider, S. A. 2002, Adv. Space Res., 29, 745

Bhardwaj, A., \& Raghuram, S. 2011, MNRAS, 412, L25

Bhardwaj, A., \& Raghuram, S. 2012, ApJ, 748, 13

Biver, N., Bockelée-Morvan, D., Colom, P., et al. 1997, Science, 275, 1915

Biver, N., Bockelée-Morvan, D., Crovisier, J., et al. 1999, AJ, 118, 1850

Biver, N., Bockelee-Morvanan, D., Crovisier, J., et al. 2007, Planet. Space Sci., 55,1058

Biver, N., Bockelée-Morvan, D., Colom, P., et al. 2009, A\&A, 501, 359

Bockelée-Morvan, D., Crovisier, J., Mumma, M. J., \& Weaver, H. A. 2004, in The composition of cometary volatiles: Comets II, eds. M. C. Festou, H. U. Keller, \& H. A. Weaver, 391

Bockelée-Morvan, D., Hartogh, P., Crovisier, J., et al. 2010, A\&A, 518, L149

Bodewits, D., Farnham, T. L., \& A'Hearn, M. F. 2012, in Am. Astron. Soc., DPS meeting, 44, 50606

Capria, M. T., Cremonese, G., Bhardwaj, A., \& de Sanctis, M. C. 2005, A\&A, 442, 1121

Capria, M. T., Cremonese, G., Bhardwaj, A., Sanctis, M. C. D., \& Epifani, E. M. 2008, A\&A, 479, 257

Capria, M. T., Cremonese, G., \& de Sanctis, M. C. 2010, A\&A, 522, A82

Cochran, W. D. 1984, Icarus, 58, 440

Cochran, A. L. 2008, Icarus, 198, 181

Cochran, A. L., \& Cochran, W. D. 2001, Icarus, 154, 381

Colangeli, L., Epifani, E., Brucato, J. R., et al. 1999, A\&A, 343, 87

Combi, M. R., Mäkinen, J. T. T., Bertaux, J. L., Lee, Y., \& Quémerais, E. 2009, AJ, 137, 4734

Combi, M. R., Mäkinen, J. T. T., Bertaux, J.-L., et al. 2013, Icarus, 225, 740

Crovisier, J., Brooke, T. Y., Hanner, M. S., et al. 1996, A\&A, 315, L385

Crovisier, J., Leech, K., Bockelée-Morvan, D., et al. 1997, Science, 275, 1904

Crovisier, J. T. E., Lellouch, E., Bockelée-Morvan, D., et al. 1999, Proc. Conf., The Universe as seen by ISO, 121, 161

Decock, A., Jehin, E., Hutsemékers, D., \& Manfroid, J. 2013, A\&A, 555, A34

Dello Russo, N., Mumma, M. J., Disanti, M. A., et al. 2000, Icarus, 143, 324

Delsemme, A. H., \& Combi, M. R. 1976, ApJ, 209, L149

Delsemme, A. H., \& Combi, M. R. 1979, ApJ, 228, 330

Farnham, T. L., Bodewits, D., A'Hearn, M. F., \& Feaga, L. M. 2012, in Am. Astron. Soc., DPS meeting, 44, 5065

Feaga, L. M., A'Hearn, M., Farnham, T., et al. 2012, in Am. Astron. Soc., DPS meeting, 44, 31308

Feldman, P. D., Festou, M. C., Tozzi, G. P., Feldman, P. D., \& Weaver, H. A. 1997, ApJ, 475, 829

Festou, M. C., \& Feldman, P. D. 1981, A\&A, 103, 154

Fink, U., \& Johnson, J. R. 1984, AJ, 89, 1565

Furusho, R., Kawakitab, H., Fusec, T., \& Watanabe, J. 2006, Adv. Space Res., 9, 1983 
S. Raghuram and A. Bhardwaj: Atomic oxygen emission lines in comets at large heliocentric distances

Haider, S. A., \& Bhardwaj, A. 2005, Icarus, 177, 196

Huebner, W. F., \& Carpenter, C. W. 1979, Los Alamos Report, 8085

Huebner, W. F., Keady, J. J., \& Lyon, S. P. 1992, Astrophys. Space Sci., 195, 1

Huestis, D. L., \& Slanger, T. G. 2006, Am. Astron. Soc., DPS meeting, 38, 62.20

Jain, S. K. 2013, Ph.D. Thesis: Dayglow emissions on Mars and Venus

McKay, A. J., Chanover, N. J., Morgenthaler, J. P., et al. 2012, Icarus, 220, 277

McKay, A. J., Chanover, N. J., Disanti, M. A., et al. 2014, Icarus, 231, 193

Meech, K. J., \& Svoreň, J. 2004, in Using Cometary Activity to Trace the Physical and Chemical Evolution of Cometary Nuclei, eds. M. C. Festou, H. A. Weaver, \& H. U. Keller (Tucson: Univ. of Arizona), 317

Morgenthaler, J. P., Harris, W. M., Scherb, F., et al. 2001, ApJ, 563, 451

Morrison, N. D., Knauth, D. C., Mulliss, C. L., \& Lee, W. 1997, Astro. Soc. Pac., 109,676

Mumma, M. J., DiSanti, M. A., Tokunaga, A., \& Roettger, E. E. 1995, BAAS, 27,1144

Mumma, M. J., DiSanti, M. A., Dello Russo, N., et al. 1996, Science, 272, 1310
Ootsubo, T., Kawakita, H., Hamada, S., et al. 2012, ApJ, 752, 1

Paganini, L., Mumma, M. J., Villanueva, G. L., et al. 2012, ApJ, 748, L13

Raghuram, S., \& Bhardwaj, A. 2012, Planet. Space Sci., 63, 139

Raghuram, S., \& Bhardwaj, A. 2013, Icarus, 223, 91

Reach, W. T., Vaubaillon, J., Lisse, C. M., Holloway, M., \& Rho, J. 2010, Icarus, 208, 276

Rosén, S., Derkatch, A., Semaniak, J., et al. 2000, Faraday Discuss., 407, 295

Schultz, D., Li, G. S. H., Scherb, F., \& Roesler, F. L. 1992, Icarus, 96, 190 Seiersen, K., Al-Khalili, A., Heber, O., et al. 2003, Phys. Rev. A, 68, 022708 Tobiska, W. K. 2004, Adv. Space Res., 34, 1736

Villanueva, G. L., Mumma, M. J., DiSanti, M. A., et al. 2012, Icarus, 220, 291

Weaver, H. A., Feldman, P. D., McPhate, J. B., et al. 1994, ApJ, 422, 374

Whipple, F. L., \& Huebner, W. F. 1976, ARA\&A, 14, 143

Woodward, C. E., Kelley, M. S., Bockelée-Morvan, D., \& Gehrz, R. D. 2007, ApJ, 671, 1065

Zhang, H. W., Zhao, G., \& Hu, J. Y. 2001, A\&A, 367, 1049 